BIS WORKING PAPERS

No 87 - May 2000

\title{
MONETARY POLICY IN AN ESTIMATED OPTIMISATION-BASED MODEL WITH STICKY PRICES AND WAGES
}

by

Jeffery D Amato and

Thomas Laubach

BANK FOR INTERNATIONAL SETTLEMENTS

Monetary and Economic Department

Basel, Switzerland 
BIS Working Papers are written by members of the Monetary and Economic Department of the Bank for International Settlements, and from time to time by other economists, and are published by the Bank. The papers are on subjects of topical interest and are technical in character. The views expressed in them are those of their authors and not necessarily the views of the BIS.

Copies of publications are available from:

Bank for International Settlements

Information, Press \& Library Services

CH-4002 Basel, Switzerland

Fax: +41 61 / 2809100 and +4161/2808100

This publication is available on the BIS website (www.bis.org).

(C) Bank for International Settlements 2000.

All rights reserved. Brief excerpts may be reproduced or translated provided the source is stated. 
BIS WORKING PAPERS

No 87 - May 2000

\title{
MONETARY POLICY IN AN ESTIMATED OPTIMISATION-BASED MODEL WITH STICKY PRICES AND WAGES
}

\author{
by \\ Jeffery D Amato and \\ Thomas Laubach*
}

\begin{abstract}
This paper serves two purposes. First, it provides estimates of an optimisationbased equilibrium model with sticky prices and wages. Second, the estimated model is used to analyse the welfare properties of various interest rate rules for conducting monetary policy. As shown by Erceg et al (1999), an important feature of this model is that it involves a trade-off between the variances of price and wage inflation and the output gap. This trade-off implies that it is desirable for the monetary authority to respond to more than inflation, output and past interest rates when setting the current interest rate. Indeed, the welfare optimal policy can be approximated with responses to both price and wage inflation and the past interest rate. By contrast, rules that call for a strong response to either detrended output or the output gap result in much lower level of welfare.
\end{abstract}

* E-mail: jeffery.amato@bis.org; Thomas Laubach, Federal Reserve Bank of Kansas City, tlaubach@frbkc.org. We gratefully acknowledge many helpful discussions with Michael Woodford, as well as comments from Mark Gertler, Peter Ireland, Julio Rotemberg, Argia Sbordone and John Taylor. All remaining errors are ours. The views expressed herein are those of the authors and do not necessarily reflect those of the Bank for International Settlements, the Federal Reserve Bank of Kansas City or the Federal Reserve System. 



\section{Contents}

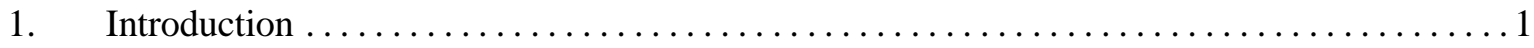

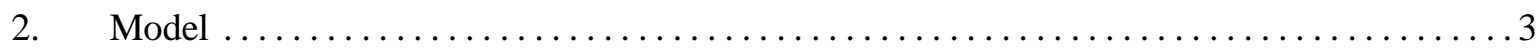

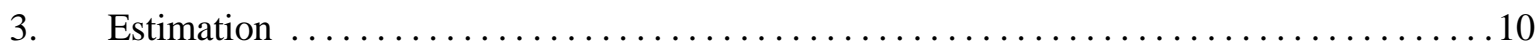

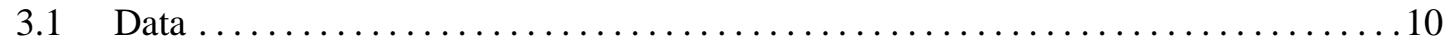

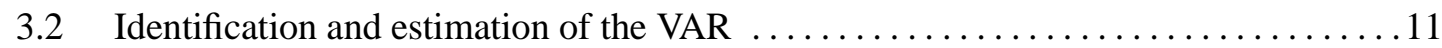

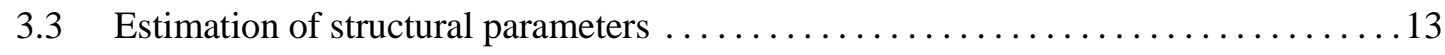

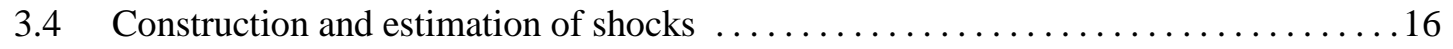

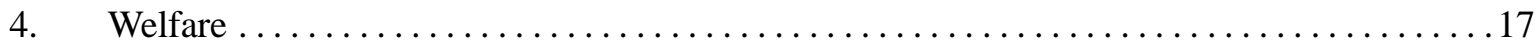

4.1 An expression for the representative household's welfare $\ldots \ldots \ldots \ldots \ldots \ldots \ldots$

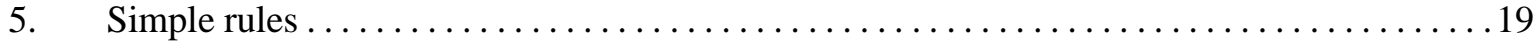

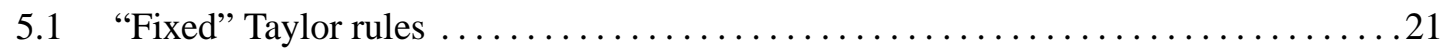

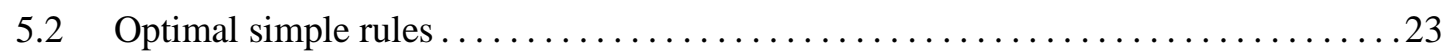

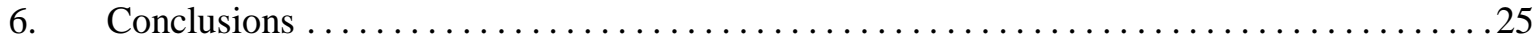

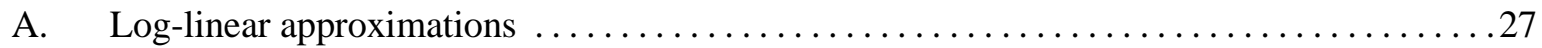

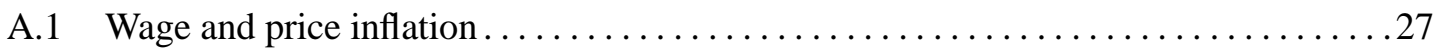

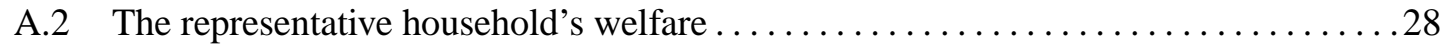

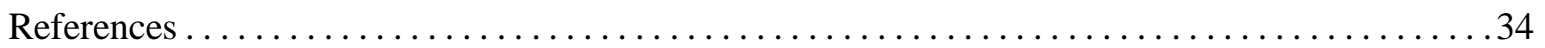





\section{Introduction}

Most recent work involving monetary policy rules has focused exclusively on the responses of interest rates to inflation, output or past interest rates, eg the recent volume by Taylor (1999a). ${ }^{1}$ The focus on these three variables has been sufficient for the models, and typically ad hoc loss functions, used in these analyses. In the context of optimisation-based models that incorporate only one nominal rigidity, stabilising inflation at zero is Pareto optimal, and this equilibrium can be approximately achieved with the simple policy of responding strongly to both current inflation and the past level of the interest rate. However, once the welfare function of households involves a variance trade-off, eg, due to the existence of a second nominal rigidity, it is no longer clear that policymakers can confine themselves to looking solely at inflation and interest rates (and perhaps output). In this paper, we estimate a model that incorporates both nominal price and wage rigidities to analyse whether in practice interest rate rules restricted to respond to only inflation, output, and past interest rates are approximately optimal in a class of simple rules.

Our model features monopolistic competition and staggered price setting in both product and labour markets. Households maximise utility by choosing consumption and setting wages in a staggered fashion. Firms maximise profits by choosing prices in a staggered fashion. This extension of the standard optimising model used in recent analyses of monetary policy is compelling for at least three reasons. First, evidence on staggered wage setting is at least as persuasive as evidence on staggered price setting. Second, as demonstrated in Erceg (1997), staggered wage setting generates a flat marginal cost schedule at the individual firm level, and hence persistent output effects of monetary shocks. Third, explicit modelling of the wage setting behaviour of households allows us to estimate directly the elasticity of labour supply, which figures prominently in household welfare and thus plays an important role in the evaluation of policy rules. ${ }^{2}$

An important first step in our analysis is to estimate our model using data for the US economy. Understanding the practical implications of various interest rate rules requires that we obtain estimates of the structural parameters and shocks. To date, however, there exist only a few studies which estimate optimisation-based models for monetary policy evaluation. In the light of the large recent literature on monetary policy rules, we find the paucity of empirical structural models to be troubling in view

1 The most notable exceptions in the analysis of optimal policy rules are models for small open economies that incorporate exchange rates, eg Batini and Haldane (1999). In the structural VAR literature that seeks to identify the effects of exogenous monetary policy shocks, and thus provides implicit models of interest rate setting, eg Bernanke and Mihov (1998), monetary aggregates and commodity prices are also included.

2 Our model is a variant of the one used by Erceg et al (1999), where we have incorporated decision lags in the consumption and wage choices of households and the pricing decisions of firms. They show that nominal price and wage stickiness together imply a variance trade-off between price and wage inflation and the output gap. 
of the Lucas (1976) critique. It is compelling to believe that agents will understand the nature of any new policy regime offered in these analyses. Furthermore, since the underlying structural parameters in an optimisation-based model play a crucial role in the welfare analysis of alternative rules, it is vital that the values of these parameters have some empirical validation from macroeconomic time series. Our estimation model is unique among those employed to analyse interest rate rules - whether based on explicit optimising foundations or not - in that we utilise data on both prices and wages to obtain estimates of the relevant inputs to our welfare analysis. ${ }^{3}$

We adopt and extend the estimation strategy of Rotemberg and Woodford (1997). The essence of this approach is to obtain estimates of the structural parameters based on impulse response functions to an exogenous monetary policy shock, and estimates of the structural shocks to replicate the remaining time series features of our endogenous variables. In addition, we show that Rotemberg and Woodford's methods are an example of minimum distance estimation, which provides us with standard errors for our estimates. The advantage of this approach versus directly specifying stochastic processes for the shocks and estimating the model by maximum likelihood, as in, for example, Kim (1999) and Ireland (1997, 1999), is that it clarifies which moments of the data are crucial for determining the structural parameters.

The second part of our analysis focuses on the welfare properties of simple interest rate rules. One contribution from this analysis is clarification of the role of output in interest rate rules. Most nonoptimising models build in a trade-off between the variances of inflation and the measure of the output gap that policymakers are assumed to care about. Therefore, it is optimal in these models for the interest rate to respond to the output gap. Conversely, the standard optimising model with only sticky prices has no such trade-off. ${ }^{4}$ Stabilising the output gap, ie stabilising only inefficient fluctuations in output, can be achieved by stabilising inflation because dispersions in output across firms are caused solely by inflation in the presence of sticky prices. Erceg et al (1999) argue that the presence of a variance trade-off in a model with both sticky prices and wages reintroduces a role for the output gap in interest rate rules and, in particular, that monetary policy can nearly achieve the welfare optimal outcome by responding to both inflation and the output gap. In contrast, we find that under our estimates for the structural parameters and shocks, a strong interest rate response to the output gap can lead to severely suboptimal outcomes.

3 In recent work, Kim (1999) estimates an optimisation-based model that embeds both sticky prices and wages, but he does not use data on wages in the formation of the likelihood function.

4 In non-optimising models, the output gap is constructed, both conceptually and empirically, as deviations of output from a smooth trend, whereas, in optimizing models, the notion of potential output is different, since it is identified as the Pareto optimal, or efficient, level of output, which in general could be very volatile. Both output itself and the efficient level of output are assumed to evolve around (the same) deterministic steady-state path, which in practice is taken to be a linear trend. 
Looking ahead to our most important results, we obtain estimates of the intertemporal elasticity of substitution in consumption and the elasticity of labour supply that are in line with evidence from panel data. Our estimate of the markup in goods markets is higher than the labour markup and both are below $20 \%$. The key implication of our estimates for policy is that near optimal outcomes can be achieved by having the interest rate respond to both price and wage inflation, as well as the lagged interest rate. The optimal response to output, whether measured as a deviation from the steady state, ie detrended output, or as the output gap, ie the deviation of output from its Pareto optimal level, is negligible. Our estimated version of a sticky price and wage model does not overturn a striking result obtained by Rotemberg and Woodford (1999) in a model with only nominal price rigidities; namely, that substantial inertia in interest rate setting is desirable. Furthermore, contrary to the conclusions of Erceg et al (1999), having the monetary authority respond to only inflation and the lagged interest rate does not lead to a substantial decline in welfare.

The remainder of the paper is organised as follows. Section 2 introduces the model. Section 3 presents our estimation methodology and results. Section 4 decribes the welfare function of the respresentative household. Section 5 analyses the welfare properties of simple interest rate rules. Section 6 concludes. An appendix provides approximations to the model equations and the welfare function.

\section{Model}

In this section, we introduce a structural model of price inflation, wage inflation and output determination similar to the model developed in Erceg et al (1999). Real effects of monetary policy in this model are due to imperfect competition and staggered price and wage setting in goods and labour markets.

The economy consists of a continuum of households and firms, and there is a continuum of differentiated, perishable goods and differentiated kinds of labour services. Each household is the monopolistic supplier of one kind of labour service, and consumes a CES aggregate of all the differentiated goods. The household sets a nominal wage for its labour services, and supplies as many hours as are demanded at its chosen wage. Each firm is the monopolistic producer for one good, and uses a CES aggregate of households' labour services in the production process. The firm sets a price for its good, and satisfies demand at this price. Because the analysis focuses on the effects of monetary policy at the business cycle horizon, capital accumulation is not modelled.

Household $i$ 's utility is defined over the index $C_{t}^{i}$, where

$$
C_{t}^{i}=\left[\int_{0}^{1} c_{t}^{i}(z)^{\frac{\theta-1}{\theta}} d z\right]^{\frac{\theta}{\theta-1}}
$$


$z$ denotes a specific good, and $\theta>1$ parameterises the elasticity of substitution in the household's preferences between the various goods. As $\theta$ gets large, goods become ever closer substitutes, whereas if $\theta$ approaches 1 from above, goods are less and less substitutable. Hence $\theta$ also measures the market power of each of the firms located on the interval [0,1], with market power decreasing in $\theta$.

The "consumption-based price index" is defined as

$$
P_{t} \equiv\left[\int_{0}^{1} p_{t}(z)^{1-\theta} d z\right]^{\frac{1}{1-\theta}}
$$

The price index $P_{t}$ denotes the minimum amount the household has to spend to obtain one unit of the composite good $C_{t}$ defined in (1). Maximising the index (1) for a given level of consumption expenditure, the household allocates consumption across individual products according to

$$
c_{t}^{i}(z)=\left[\frac{p_{t}(z)}{P_{t}}\right]^{-\theta} C_{t}^{i}
$$

Household $i$ is the sole supplier of labour services $h^{i}$, and its objective is to maximise

$$
E_{0}\left[\sum_{t=0}^{\infty} \beta^{t}\left(u\left(C_{t}^{i} ; \xi_{t}\right)-v\left(h_{t}^{i} ; \zeta_{t}\right)\right)\right]
$$

subject to a demand schedule for its labour services and the budget constraint

$$
E_{t}\left[\delta_{t, t+1} A_{t+1}^{i}\right] \leq A_{t}^{i}+W_{t}^{i} h_{t}^{i}+\Pi_{t}-P_{t} C_{t}^{i}
$$

Within each period, the household derives utility $u\left(\cdot ; \xi_{t}\right)$ from consumption $C_{t}^{i}$ as defined in (1), while supplying hours $h_{t}^{i}$ reduces utility, as indicated by the function $v\left(\cdot ; \zeta_{t}\right)$. In the budget constraint, $P_{t}$ denotes the price index defined in (2), and $A_{t}$ denotes the nominal value of the household's holdings of financial assets at the beginning of period $t . W_{t}^{i}$ is the hourly wage that household $i$ charges, and $\Pi_{t}$ the household's share in firms' profits, which we assume are distributed lump-sum to households. $\delta_{t, \tau}$ is a stochastic discount factor, pricing in period $t$ assets whose payoffs are in period $\tau$. Financial markets are assumed to be complete, and in particular there exists a riskless one-period nominal bond, the gross return on which is given by $R_{t} \equiv\left(E_{t} \delta_{t, t+1}\right)^{-1}$. The stochastic disturbance $\xi_{t}$ is interpreted as a preference or "demand" shock, while $\zeta_{t}$ is a disturbance to labour supply. The household's choice variables are consumption and hours or, given the demand function for its labour services, its wage.

Firm $z$ is the monopolistic supplier of good $z$, which it produces according to the production function

$$
y_{t}(z)=e^{\eta_{t}} \bar{K}^{a} H_{t}(z)^{1-a}
$$


where $\eta_{t}$ denotes a stochastic technology disturbance, the capital stock employed by each firm is fixed at $\bar{K}$, and the firm's labour input is a CES aggregate of different households' labour services

$$
H_{t}(z)=\left[\int_{0}^{1} h_{t}^{i}(z)^{\frac{\phi-1}{\phi}} d i\right]^{\frac{\phi}{\phi-1}}
$$

The parameter $\phi>1$ characterises the elasticity of substitution between the various types of labour services. The wage index $W_{t}$ is defined as

$$
W_{t} \equiv\left[\int_{0}^{1}\left(W_{t}^{i}\right)^{1-\phi} d i\right]^{\frac{1}{1-\phi}}
$$

Maximising the index (7) for a given level of wage payments, firm $z$ allocates demand for individual labour services according to

$$
h_{t}^{i}(z)=\left[\frac{W_{t}^{i}}{W_{t}}\right]^{-\phi} H_{t}(z)
$$

Aggregate demand for output is defined as $Y_{t}=C_{t}+G_{t}$, where $C_{t} \equiv \int_{0}^{1} C_{t}^{i} d i$, and $G_{t}$ is an exogenously given component of demand for output, which is assumed to be determined one period ahead. Assuming that $G_{t}$ is allocated across the different goods by maximising an index defined analogously to the consumption index (1), the demand faced by firm $z$ is given by

$$
y_{t}(z)=\left[\frac{p_{t}(z)}{P_{t}}\right]^{-\theta} Y_{t} .
$$

Analogously, by integrating (9) across firms, the demand for its labour services faced by household $i$ is

$$
h_{t}^{i}=\left[\frac{W_{t}^{i}}{W_{t}}\right]^{-\phi} H_{t}
$$

where $H_{t} \equiv \int_{0}^{1} H_{t}(z) d z$.

We now characterise households' utility-maximising consumption and wage decisions, and firms' profitmaximising price choices. Because we wish to use solution methods for linear rational expectations models, the equilibrium conditions we use are log-linear approximations to the exact, non-linear firstorder conditions of households and firms. For reasons discussed in Woodford (1999a), the welfare analysis later on is facilitated by log-linearising around the efficient steady state, ie the steady state corresponding to a situation without market power and nominal rigidities in goods and labour markets. The efficient steady state level of output is determined by the condition that households' marginal rate of substitution between labour and consumption equals the marginal product of labour, ie

$$
\frac{v_{h}(H(\bar{Y}) ; 0)}{u_{c}(\bar{Y}-\bar{G} ; 0)}=(1-a)(\bar{Y} / \bar{K})^{-\frac{a}{1-a}}
$$

where $\bar{Y}$ and $\bar{G}$ denote the steady state values of output and exogenous demand respectively. The presence of market power of households and firms implies that, in the absence of some offsetting policy, the steady state output level is below this efficient level of output. To justify log-linearising the exact 
equilibrium conditions around the efficient steady state, below we will have to assume that tax policies are in place which offset the inefficiencies caused by imperfect competition in goods and labour markets. Furthermore, we log-linearise around a steady state in which there is zero price and wage inflation.

Households are assumed to choose their consumption purchases two periods ahead, ie $C_{t}^{i}$ is chosen in $t-2 .{ }^{5}$ The decision lag for consumption implies that the household's Euler equation takes the form

$$
E_{t} u_{c}\left(C_{t+2}^{i} ; \xi_{t+2}\right)=E_{t} \lambda_{t+2}^{i} P_{t+2}
$$

where $\lambda_{t}^{i}$ denotes household $i$ 's marginal utility of income at date $t$. Since households are free to take investment decisions each period with immediate effect, $\lambda_{t}$ has to satisfy

$$
\lambda_{t}=\beta E_{t}\left[R_{t} \lambda_{t+1}\right]
$$

Dropping the superscript $i$ implicitly assumes that, because of complete markets, households insure themselves against all idiosyncratic risk, and therefore the path of consumption is identical across households. Let $\hat{\lambda}_{t}$ denote the percentage deviation of $\lambda_{t} P_{t}$ from its steady state value. Then the loglinear approximation of (14) is

$$
\begin{aligned}
\hat{\lambda}_{t} & =E_{t}\left[\hat{R}_{t}-\pi_{t+1}+\hat{\lambda}_{t+1}\right] \\
& =\sum_{T=t}^{\infty} E_{t}\left[\hat{R}_{T}-\pi_{T+1}\right]
\end{aligned}
$$

where $\hat{R}_{t}$ is the percentage deviation of the interest rate from its steady state value consistent with zero inflation. The log-linear approximation of the Euler equation (13) is therefore

$$
-\tilde{\sigma} E_{t}\left[\hat{C}_{t+2}-\tilde{\xi}_{t+2}\right]=\sum_{T=t+2}^{\infty} E_{t}\left[\hat{R}_{T}-\pi_{T+1}\right]
$$

where $\hat{C}_{t} \equiv\left(C_{t}-\bar{C}\right) / \bar{C}$ denotes the percentage deviation of consumption from its steady state value $\bar{C}, \tilde{\sigma} \equiv-u_{c c}(\bar{C}) \bar{C} / u_{c}(\bar{C})$, and $\tilde{\xi}_{t} \equiv-\left(u_{c \xi}(\bar{C}) / u_{c c}(\bar{C}) \bar{C}\right) \xi_{t}$ is the disturbance to the marginal utility of consumption.

Log-linearising aggregate demand around the steady state yields

$$
\hat{Y}_{t}=s_{c} \hat{C}_{t}+\tilde{G}_{t}
$$

\footnotetext{
5 Although this choice of decision lag is somewhat arbitrary, it is no more arbitrary than choosing to specify our model at a quarterly frequency - or, for that matter, any frequency - in the absence of compelling evidence to the contrary. As in Rotemberg and Woodford (1997), we choose a two-quarter lag to match the timing of the maximum impact of a monetary policy shock on output in our model to that in the VAR. Instead, we could introduce and estimate a free parameter that captures the average decision lag of households due to, eg, time-to-build constraints.
} 
where $\hat{Y}_{t} \equiv\left(Y_{t}-\bar{Y}\right) / \bar{Y}, \tilde{G}_{t} \equiv\left(G_{t}-\bar{G}\right) / \bar{Y}$, and $s_{c} \equiv \bar{C} / \bar{Y}$. By substituting from the log-linearised aggregate demand equation for $C_{t}$, the Euler equation can be written as

$$
\hat{Y}_{t}=-\sigma^{-1} E_{t-2} \sum_{T=t}^{\infty}\left[\hat{R}_{T}-\pi_{T+1}\right]+\hat{G}_{t}
$$

where $\sigma \equiv \tilde{\sigma} / s_{c} \equiv-u_{c c}(\bar{C}) \bar{Y} / u_{c}(\bar{C})$, and $\hat{G}_{t} \equiv \tilde{G}_{t}+s_{c} E_{t-2} \tilde{\xi}_{t}$. Equation (19) is the model's "IS equation".

The assumption for wage and price adjustment we use is Rotemberg and Woodford's (1997) variant of Calvo's (1983) staggered price setting. Each period, a fraction $1-\lambda$ of households is chosen, at random and independent of their individual histories, and is offered the opportunity to set a new wage. Hence, from the perspective of an individual household, the wage set in period $t$ applies with probability 1 in period $t$, with probability $\lambda$ in period $t+1$, with probability $\lambda^{2}$ in period $t+2$ and so forth. Rotemberg and Woodford assume furthermore that at the end of period $t-1$, a fraction $\gamma^{w}$ of those households who choose a new wage can apply this wage beginning at date $t$, the remaining fraction $1-\gamma^{w}$ applies this wage beginning at date $t+1$. Let $W_{t}^{1}$ denote the wage chosen in $t-1$ by those households whose wage comes into effect in period $t$, and let $W_{t}^{2}$ denote the wage chosen in $t-2$ by those households whose wage comes into effect in $t$. The aggregate wage level is then given by

$$
W_{t}=\left[\lambda W_{t-1}^{1-\phi}+(1-\lambda) \gamma^{w}\left(W_{t}^{1}\right)^{1-\phi}+(1-\lambda)\left(1-\gamma^{w}\right)\left(W_{t}^{2}\right)^{1-\phi}\right]^{\frac{1}{1-\phi}}
$$

The wage $W_{t}^{1}$ is chosen to maximise

$$
E_{t-1} \sum_{T=t}^{\infty}(\lambda \beta)^{T-t}\left[\lambda_{T}\left(1+\tau_{w}\right) W_{t}^{1}\left(\frac{W_{t}^{1}}{W_{T}}\right)^{-\phi} H_{T}-v\left(\left(\frac{W_{t}^{1}}{W_{T}}\right)^{-\phi} H_{T} ; \zeta_{T}\right)\right]
$$

Since the wage chosen at the end of period $t-1$ will apply at time $t$ with probability 1 , at time $t+1$ with probability $\lambda$ and so forth, the household discounts utility in future periods conditional on $W_{t}^{1}$ still applying by $(\lambda \beta)^{T-t}$. Marginal utility of income at any point in time is the same across households. Therefore, the household's utility from charging wage $W_{t}^{1}$ in period $T$ is given by the product of marginal utility of income and earnings (the first term in brackets) less the disutility from supplying $\left(W_{t}^{1} / W_{T}\right)^{-\phi} H_{T}$, the number of hours demanded at wage $W_{t}^{1}$ and aggregate wages and hours $W_{T}$ and $H_{T}$ (the second term in brackets). $\tau_{w}$ denotes a subsidy for employment. By choosing $\tau_{w}=(\phi-1)^{-1}$, the effect of imperfect competition in labour markets on the steady state output level can be offset.

The first-order condition for $W_{t}^{1}$ can be expressed as

$$
\begin{aligned}
E_{t-1} & \sum_{T=t}^{\infty}(\lambda \beta)^{T-t}\left(\frac{W_{t}^{1}}{W_{T}}\right)^{-\phi} H_{T} \\
\cdot & {\left[v_{h}\left(\left(\frac{W_{t}^{1}}{W_{T}}\right)^{-\phi} H_{T} ; \zeta_{T}\right)-\frac{\phi-1}{\phi} \lambda_{T} P_{T}\left(1+\tau_{w}\right) \frac{W_{t}^{1}}{P_{T}}\right]=0 }
\end{aligned}
$$


Households choose their nominal wage in period $t-1$ such that the discounted sum of expected future real wages $\left(1+\tau_{w}\right) W_{t}^{1} / P_{T}$ equals the discounted sum of expected future marginal rates of substitution between consumption and leisure $v_{h}\left(h_{t, T}^{1} ; \zeta_{T}\right) /\left(\lambda_{T} P_{T}\right)$ times a markup $\frac{\phi}{\phi-1}$, where we used $h_{t, T}^{1}$ as shorthand for the number of hours supplied in period $T$ at wage $W_{t}^{1}$.

In the Appendix, we derive a log-linear approximation to this first-order condition. Using this log-linear approximation as well as the corresponding relation for $W_{t}^{2}$ and the log-linear approximation of the wage index (20), we obtain the following law of motion for the rate of wage inflation $\pi_{t}^{w} \equiv \log \left(W_{t} / W_{t-1}\right)$ :

$$
\begin{aligned}
\pi_{t}^{w}= & \left(1-\psi^{w}\right) E_{t-2} \pi_{t}^{w} \\
& +\psi^{w}\left[\kappa^{w}\left(\hat{Y}_{t}-\hat{Y}_{t}^{w}\right)-\frac{\kappa^{w}(1-a)}{\omega+\sigma(1-a)}\left(\hat{w}_{t}+\nu_{t-1}\right)+\beta E_{t-1} \pi_{t+1}^{w}\right]
\end{aligned}
$$

The parameter $\omega \equiv v_{h h}(\bar{H} ; 0) \bar{H} / v_{h}(\bar{H} ; 0)$ measures the elasticity of the disutility of labour supply at the steady state level of hours $\bar{H}$. The coefficient

$$
\kappa^{w} \equiv \frac{(1-\lambda)(1-\lambda \beta)}{\lambda} \frac{\omega+\sigma(1-a)}{(1+\phi \omega)(1-a)}
$$

describes the elasticity of wage inflation with respect to the gap between actual output $\hat{Y}_{t}$ and

$$
\hat{Y}_{t}^{w} \equiv \frac{1-a}{\omega+\sigma(1-a)} E_{t-1}\left[\frac{\omega}{1-a} \eta_{t}+\omega \tilde{\zeta}_{t}+\sigma \hat{G}_{t}\right]
$$

the level of output consistent with stable wage inflation. The coefficient $\psi^{w} \equiv \gamma^{w} \lambda /\left(1-\gamma^{w}(1-\lambda)\right)$ equals 1 for $\gamma^{w}=1$, the case in which all wage adjustments are effective the following period. The term $\hat{w}_{t} \equiv \log \left(W_{t} / P_{t}\right)$ denotes the percentage deviation of the real wage from its steady state. Positive deviations of the real wage from steady state reduce wage inflation. Finally,

$$
\nu_{t-1} \equiv E_{t-1} \sum_{T=t}^{\infty}\left(\hat{R}_{T}-\pi_{T+1}\right)-E_{t-2} \sum_{T=t}^{\infty}\left(\hat{R}_{T}-\pi_{T+1}\right)
$$

is the revision from $t-2$ to $t-1$ expectations of the long-term real interest rate in period $t$. Such revisions reduce wage inflation because they raise the returns households expect from their future earnings.

Price adjustment by firms is modelled analogously to wage adjustment by households. Each period, a fraction $1-\alpha$ of firms is chosen, at random and independent of their individual histories, and is offered the opportunity to adjust their price. At the end of period $t-1$, a fraction $\gamma^{p}$ of those who choose a new price can apply this price beginning at date $t$, the remaining fraction $1-\gamma^{p}$ applies this price beginning at date $t+1$. Let $p_{t}^{1}$ denote the price chosen in $t-1$ by those firms whose price comes into effect in period $t$, and let $p_{t}^{2}$ denote the price chosen in $t-2$ by those firms whose price comes into effect in $t$. The aggregate price level is then given by

$$
P_{t}=\left[\alpha P_{t-1}^{1-\theta}+(1-\alpha) \gamma^{p}\left(p_{t}^{1}\right)^{1-\theta}+(1-\alpha)\left(1-\gamma^{p}\right)\left(p_{t}^{2}\right)^{1-\theta}\right]^{\frac{1}{1-\theta}}
$$


The price $p_{t}^{1}$ is chosen to maximise

$$
E_{t-1} \sum_{T=t}^{\infty} \alpha^{T-t} \delta_{t, T}\left[\left(1+\tau_{p}\right) p_{t}^{1}\left(\frac{p_{t}^{1}}{P_{T}}\right)^{-\theta} Y_{T}-W_{T}\left(\left(\frac{p_{t}^{1}}{P_{T}}\right)^{-\theta} \frac{Y_{T}}{e^{\eta_{T}}}\right)^{\frac{1}{1-a}}\right]
$$

Since the price chosen at the end of period $t-1$ will apply at time $t$ with probability 1 , at time $t+1$ with probability $\alpha$ and so forth, the firm discounts future profits conditional on $p_{t}^{1}$ still applying by $\alpha^{T-t} \delta_{t, T}$, where $\delta_{t, T}$ is the stochastic discount factor introduced in (5). The first term in brackets denotes revenues in period $T$ at price $p_{t}^{1}$, the second term the firm's labour cost implied by the level of output that is demanded in period $T$ at price $p_{t}^{1} . \tau_{p}$ denotes a subsidy for producing output. By choosing $\tau_{p}=(\theta-1)^{-1}$, the effect of imperfect competition in goods markets on the steady state output level can be offset.

The first-order condition with respect to $p_{t}^{1}$ can be written as

$$
\begin{aligned}
E_{t-1} & \sum_{T=t}^{\infty} \alpha^{T-t} \delta_{t, T}\left(\frac{p_{t}^{1}}{P_{T}}\right)^{-\theta} Y_{T} \\
& \cdot\left[\left(1+\tau_{p}\right) p_{t}^{1}-\frac{\theta}{\theta-1}(1-a)^{-1} e^{\frac{-\eta_{T}}{1-a}} W_{T}\left(\left(\frac{p_{t}^{1}}{P_{T}}\right)^{-\theta} Y_{T}\right)^{\frac{a}{1-a}}\right]=0 .
\end{aligned}
$$

Firms set the price in period $t-1$ such that the price, adjusted for the subsidy, equals a weighted average of expected future marginal cost at the level of output demanded at price $p_{t}^{1}$, times a markup $\frac{\theta}{\theta-1}$.

A log-linear approximation to this first-order condition is derived in the Appendix. Using this log-linear approximation as well as the corresponding relation for $p_{t}^{2}$ and the log-linear approximation of the price index (25), the law of motion for the rate of price inflation $\pi_{t} \equiv \log \left(P_{t} / P_{t-1}\right)$ is given by

$$
\pi_{t}=\left(1-\psi^{p}\right) E_{t-2} \pi_{t}+\psi^{p}\left[\kappa^{p}\left(\hat{Y}_{t}-\hat{Y}_{t}^{p}\right)+\frac{\kappa^{p}(1-a)}{a} \hat{w}_{t}+\beta E_{t-1} \pi_{t+1}\right] .
$$

The coefficient

$$
\kappa^{p} \equiv \frac{(1-\alpha)(1-\alpha \beta)}{\alpha} \frac{a}{1-a+\theta a}
$$

denotes the elasticity of price inflation with respect to the gap between actual output $\hat{Y}_{t}$ and

$$
\hat{Y}_{t}^{p} \equiv a^{-1} E_{t-1} \eta_{t},
$$

the level of output consistent with stable price inflation. The coefficient $\psi^{p} \equiv \gamma^{p} \alpha /\left(1-\gamma^{p}(1-\alpha)\right)$ equals 1 for $\gamma^{p}=1$, the case in which all price adjustments are effective the following period. Unlike in the wage inflation equation, positive deviations of the real wage from steady state increase price inflation.

In addition to the IS and wage and price inflation equations, a fourth structural equation is necessary to determine the paths of the four endogenous variables $\left\{\hat{Y}_{t}, \pi_{t}, \pi_{t}^{w}, \hat{R}_{t}\right\}$. For the estimation of this model, monetary policy is assumed to be described by a feedback rule for the one-period nominal interest rate 
of the form

$$
\hat{R}_{t}=\sum_{k=1}^{3} \mu_{k} \hat{R}_{t-k}+\sum_{k=0}^{2} \psi_{k} \hat{w}_{t-k}+\sum_{k=0}^{2} \phi_{k} \pi_{t-k}+\sum_{k=0}^{2} \theta_{k} \hat{Y}_{t-k}+\epsilon_{t}
$$

To summarise, the model consists of the IS equation (19), the wage inflation equation (23), the price inflation equation (28) and the feedback rule for the interest rate (30). Except for stochastic disturbances, wage and price inflation in this model are predetermined one period ahead, output two periods ahead. The structural disturbances of the model are $\hat{G}_{t}, \hat{Y}_{t}^{w}, \hat{Y}_{t}^{p}$, and $\epsilon_{t}$. The first three of these shocks are themselves predetermined one period ahead, and so are wage and price inflation and output. The model parameters are the structural parameters, $\beta, \sigma, \omega, a, \alpha, \theta, \gamma^{p}, \lambda, \phi, \gamma^{w}$, and the parameters of the feedback rule (30).

\section{Estimation}

This section discusses and presents results of estimation of the model parameters and the shocks. We adopt the estimation strategy of Rotemberg and Woodford (1997), which we motivate as an example of minimum distance estimation. The estimation process has three steps. The first step is to construct and estimate a vector autoregression (VAR) for the model's four endogenous variables. This provides estimates of the interest rate rule (30). The second and third steps are to choose the model's structural parameters and structural shocks, respectively, based on subsets of the first and second moments of our data series as captured by the VAR. In particular, the structural parameters are chosen so that the responses of the endogenous variables in the model to an exogenous monetary policy shock, $\epsilon_{t}$, match as closely as possible the responses estimated from the VAR. Given the estimates of the VAR and the structural parameters, the shock processes are chosen so that the model responses of output, inflation and the real wage to perturbations in the three unidentified shocks in the VAR match exactly the responses of those variables in the VAR to the shocks. ${ }^{6}$ We elaborate on this approach below before turning to a discussion of the results. First, we describe our data.

\subsection{Data}

Our data set is for the United States. It is comprised of quarterly observations on real (chain-weighted) GDP, the GDP deflator, compensation per hour in the non-farm business sector, and the federal funds rate. ${ }^{7}$ Because we wish to identify the historical interest rate rule from the VAR, it is important that the VAR be estimated over a sample period in which policy can be characterised by an interest rate rule

\footnotetext{
6 In fact, since the shock processes must be specified in order to solve for the rational expectations equilibrium, and because the shocks are constructed from estimates of the structural parameters, the structural parameters and shocks are determined jointly.

7 Quarterly values of the federal funds rate are computed as within-quarter averages of (effective) daily rates.
} 
with constant coefficients. Several empirical studies of US monetary policy have identified a change in policy behaviour around the beginning of the Volcker chairmanship in 1979 (eg Clarida et al (1998)). By contrast, policy since the disinflation of the early 1980s has displayed a high degree of stability in the sense of being well described by a rule like (30). We therefore choose a sample period ranging from 1980:Q1 to 1997:Q4.

We present empirical results in terms of the real wage instead of wage inflation because we find impulse responses of the real wage more convenient to interpret and, in other work, the effects of monetary policy on wages are measured as effects on real wages, not wage inflation. Given our definition of variables in the previous subsection, the two are linked by $\pi_{t}^{w}=\hat{w}_{t}-\hat{w}_{t-1}+\pi_{t}$.

To express the data in a way conformable with the theoretical series $\left\{\hat{Y}_{t}, \pi_{t}, \hat{w}_{t}, \hat{R}_{t}\right\}$ of the model, real GDP is logarithmised and a linear trend is removed, inflation is computed as log first differences of the GDP deflator, the real wage is computed as the logarithm of compensation per hour deflated by the GDP deflator and a linear trend is removed, and the federal funds rate is expressed at a quarterly rate. Let $\left\{y_{t}, \pi_{t}, w_{t}, r_{t}\right\}$ denote these series, which are conformable with their theoretical counterparts up to a constant.

\subsection{Identification and estimation of the VAR}

The theoretical model implies that, because they are predetermined, output, inflation and the real wage are not contemporaneously affected by an interest rate innovation, while the form of the interest rate rule (30) allows for contemporaneous feedback from output, inflation and the real wage to the interest rate. This is sufficient to identify the parameters of the historical interest rate rule and the series of interest rate innovations $\left\{\epsilon_{t}\right\}$. Let $Z_{t}=\left(r_{t}, w_{t+1}, \pi_{t+1}, y_{t+1}\right)^{\prime}$, and let $\bar{Z}_{t}=\left(Z_{t}^{\prime}, Z_{t-1}^{\prime}, Z_{t-2}^{\prime}\right)^{\prime}$. The reason for defining $Z_{t}$ in this manner is that the elements of $Z_{t}$ all belong to the period $t$ information set, since output, inflation and the real wage are predetermined. The structural form of a $\operatorname{VAR}(3)$ in $Z_{t}$ can then be written as

$$
T \bar{Z}_{t}=m+A \bar{Z}_{t-1}+\bar{e}_{t}
$$

where $T$ is an identity matrix with a lower triangular 4 by 4 submatrix in the upper left corner, the first four rows of $A$ contain coefficients, and the last eight rows of the VAR are identities. Accordingly, the last eight elements of $\bar{e}_{t}$ are zeros. The first four elements are mutually orthogonal, so that the first four diagonal elements of the covariance matrix $V$ of $\bar{e}_{t}$ are distinct from zero, and all remaining elements 
of $V$ are zero. Under our identifying assumption, the first row of $A$ contains the coefficients of the historical interest rate rule (30), and the first element of $\bar{e}_{t}$ is $\epsilon_{t}{ }^{8}$

Table 1

\section{Estimates of reaction function in VAR}

\begin{tabular}{||c|c||c|c||c|c||}
\hline$\mu_{1}$ & 0.49 & $\mu_{2}$ & -0.04 & $\mu_{3}$ & 0.2 \\
$\psi_{0}$ & -0.06 & $\psi_{1}$ & -0.02 & $\psi_{2}$ & 0.01 \\
$\phi_{0}$ & 0.08 & $\phi_{1}$ & 0.04 & $\phi_{2}$ & 0.56 \\
$\theta_{0}$ & 0.59 & $\theta_{1}$ & 0.04 & $\theta_{2}$ & -0.46 \\
$\sum_{k=1}^{3} \mu_{k}$ & 0.65 & $\sigma_{\epsilon}$ & 0.78 & & \\
\hline
\end{tabular}

The recursive structure of the VAR allows us to estimate the equations in (31) by the OLS method. Table 1 shows estimates of the reaction function (30). While it is difficult to interpret estimates from a reduced-form equation such as (30), it is worthwhile to point out that the sum of coefficients on lagged federal funds rates is 0.65 , implying that monetary policy exhibited a great deal of inertia over this period. ${ }^{9}$ As we will see below, and for essentially the reasons articulated by Woodford (1999b), an even greater degree of inertia in interest rate setting is desirable. The solid lines in the panels of Figure 1 show the estimated impulse responses of output, inflation, the real wage, and the interest rate to an exogenous increase in the interest rate of $1 \%$. The dashed lines are two standard deviation confidence intervals. ${ }^{10}$ Due to our identifying assumption, output, inflation and the real wage do not respond during the quarter of the interest rate innovation. Output hardly responds during the following quarter, then falls in the second quarter after the innovation, before gradually returning to its original level over the following eight quarters. Inflation initially reacts faster than output to the innovation, but then oscillates between negative and near zero values, returning more slowly to its original level. The real wage responds very little at first, before turning negative in quarters three and four after the shock and positive thereafter, again slowly returning to its original level. ${ }^{11}$ A caveat to these results is that the

8 As pointed out above, the series $\left\{y_{t}, \pi_{t}, w_{t}, r_{t}\right\}$ are conformable with their theoretical counterparts up to constants. By including the constant $m$ in the VAR, the coefficients in the first row of $A$ can be interpreted as the coefficients in (30).

9 Our estimate of inertial policy does not necessarily imply that the Federal Reserve had a smoothing motive in setting interest rates. The lagged interest rates could simply be proxies for missing variables which themselves exhibit a high degree of serial correlation (see Amato and Laubach (1999)).

10 The algorithm used for bootstrapping the confidence intervals is that of Berkowitz and Kilian (1996).

11 Remarkably little work has been done on the response of wages to exogenous monetary policy shocks. Two notable exceptions are Christiano et al (1997) and Leeper et al (1996). Using different identifying assumptions and econometric methods, both sets of authors nonetheless find a weak response of the real wage to a monetary policy shock similar to what we find up to five quarters after the shock. As in Figure 1, these studies also report periods in which the response is positive, while the hypothesis of no response in any period cannot be rejected at standard levels. 
uncertainty around all four impulse response functions is considerable, although the wide confidence intervals do not necessarily imply that all parameter estimates based on matching the impulse response functions will be similarly uncertain.

\subsection{Estimation of structural parameters}

The information about the second moments of the series is summarised in the matrices $T, A$ and $V$. To illustrate how the structural parameters and shocks are obtained from estimates of these matrices, some notation may be helpful. Let $L_{1}$ denote a quadratic form describing the differences between the four variables' impulse responses to a monetary policy shock implied by the model and those estimated from the VAR, and let $L_{2}$ denote a quadratic form describing these same differences between the impulse responses to $\bar{e}_{2 t}, \bar{e}_{3 t}$ and $\bar{e}_{4 t}$. Furthermore, let $P_{1}$ denote the vector of structural parameters, ie $\sigma, \omega, a, \alpha, \theta, \gamma^{p}, \lambda, \phi, \gamma^{w}$, and let $P_{2}$ denote the vector of parameters characterising the processes $\left\{\hat{G}_{t}, \hat{Y}_{t}^{w}, \hat{Y}_{t}^{p}\right\}{ }^{12}$ Note that the structural disturbances $\left\{\hat{G}_{t}, \hat{Y}_{t}^{w}, \hat{Y}_{t}^{p}\right\}$, because of their interpretation as shocks to aggregate demand and potential output, do not necessarily have to be i.i.d., but may follow a more complex process. ${ }^{13}$ With this notation, the problem of estimating the structural parameters and shock parameters can be described as

$$
\min _{P_{1}, P_{2}} L_{1}\left(P_{1}, P_{2}\right)+L_{2}\left(P_{1}, P_{2}\right)
$$

A first observation is that, if the structural disturbances $\left\{\hat{G}_{t}, \hat{Y}_{t}^{w}, \hat{Y}_{t}^{p}\right\}$ are exogenous and orthogonal to $\left\{\epsilon_{t}\right\}$, the impulse responses to the monetary policy shock do not contain any information about the structural disturbances, and hence $L_{1}$ depends on $P_{1}$ only. Second, Rotemberg and Woodford show that for any choice of $P_{1}$, the structural disturbances can be chosen such as to perfectly match the impulse response functions to innovations in these shocks implied by the model to the VAR's impulse responses to $\bar{e}_{2 t}, \bar{e}_{3 t}$, and $\bar{e}_{4 t}$, ie

$$
\min _{P_{2}} L_{2}\left(P_{1}, P_{2}\right)=0 \forall P_{1}
$$

These two observations prompt us to estimate parameters $P_{1}$ by minimising $L_{1}$, and then compute $P_{2}$ such that $L_{2}=0$. Furthermore, write $L_{1}\left(P_{1}\right) \equiv g\left(P_{1} ; \mathbf{Y}_{T}\right)^{\prime} g\left(P_{1} ; \mathbf{Y}_{T}\right)$, where the distance function $g(\cdot, \cdot)$ is a vector-valued function containing the differences between the model's and the VAR's responses of all four endogenous variables to a monetary policy shock and $\mathbf{Y}_{T}$ contains a history of the data. Then the estimator of $P_{1}$ obtained from minimising $L_{1}\left(P_{1}\right)$ is a minimum distance estimator with an identity weighting matrix.

\footnotetext{
12 As discussed below, we can obtain an estimate of $\beta$ from the first moments of the data as captured in the vector $m$.

13 For illustrative purposes, the specification of $P_{2}$ presupposes that some assumption about the functional form of these processes has been made.
} 
Turning to identification of the structural parameters, note that $\beta$ can be recovered from the first moments of the data. Since $\beta^{-1}$ is the steady state gross real rate of return in our model, and the average ex post real interest rate in our sample is $1 \%$ (on a quarterly basis), we set $\beta$ equal to 0.99 . Unfortunately, inspection of the model equations (19), (23) and (28), reveals that not all of the other parameters are separately identified. The three parameters $\alpha, \theta$ and $\gamma^{p}$ appear in the model only through $\kappa^{p}$ and $\psi^{p}$ in the price inflation equation (28); therefore, at most two of these parameters can be estimated. Likewise, we can estimate only two of the three parameters $\lambda, \phi$ and $\gamma^{w}$, since they appear in the model only through $\kappa^{w}$ and $\psi^{w}$ in the wage inflation equation (23). Based on several survey studies, we follow Rotemberg and Woodford by setting $\alpha \equiv 0.66$, which implies that prices remain unchanged on average for three quarters. Similarly, we impose $\lambda \equiv 0.66$. Although $\gamma^{p}, \gamma^{w}$ and $\omega$ are each identified (given values for $\alpha$ and $\lambda$ ), the ratio $\gamma^{w} / \gamma^{p}$ and $\omega$ are not separately well-determined from the data. Since the value of $\omega$ has much stronger implications for the welfare analysis to follow, we fix $\gamma^{w} \equiv \gamma^{p}$, which has the interpretation of imposing equal measures of exogenous rigidity in prices and wages (under the assumption $\alpha \equiv \lambda) .{ }^{14}$ Of course, since it is $\psi^{p}$ and $\psi^{w}$ that are separately identified, and not $\gamma^{p}$ and $\gamma^{w}$, fixing $\gamma^{w} / \gamma^{p}$ is somewhat artificial. We could change the values for $\alpha$ and $\lambda$, thereby getting different estimates for $\gamma^{p}$ and $\gamma^{w}$, without affecting the fit of our model. Finally, following Rotemberg and Woodford (1997), we set $a$ equal to 0.25. Due to the presence of monopolistic competition, $a$ equals one minus the product of labour's share in firm $z$ and firm $z$ 's price markup. Our choice of $a$ will prove to be consistent with a steady-state labour share of 0.63 . Given these values, the remaining parameters $\sigma, \omega, \gamma^{p}, \kappa^{p}$ and $\kappa^{w}$ are estimated by the minimum distance method described above. We seek to minimise the difference between the model's and the VAR's responses for all four endogenous variables during quarters 1 to 5 following a monetary policy shock in quarter 0 .

The estimates for $\sigma, \omega, \gamma^{p}, \kappa^{p}$ and $\kappa^{w}$, and the implied values for $\gamma^{w}, \theta$ and $\phi$, are displayed in Table 2 (standard errors are in parentheses). ${ }^{15}$ The estimate of $\sigma$ implies an elasticity of intertemporal substitution of consumption of 3.9. This is larger than what has been found in the non-durable

14 The unrestricted estimate of $\omega$ is -0.1 and $\gamma^{w} / \gamma^{p}$ is 0.3 . However, there is only a $0.1 \%$ difference between the objective attained in unrestricted estimation and that obtained by imposing the restriction $\gamma^{w} / \gamma^{p}=1$. The parameter $\gamma^{p}$ is largely determined by the first-quarter response of inflation to a shock, but the ratio $\gamma^{w} / \gamma^{p}$ affects the entire path response of the real wage to shocks, as does the parameter $\omega$. Increasing $\gamma^{w} / \gamma^{p}$ ceteris paribus has the effect of strengthening the response of the real wage to a monetary shock, especially early on (since, in this case, wages respond more quickly to the shock than prices), while increasing $\omega$ ceteris paribus has the opposite effect on the response of the real wage, with a relatively bigger impact in later quarters (since workers are less willing to substitute labour over time, which is especially binding in the presence of sticky wages in the short term).

15 Standard errors are calculated from the asymptotic covariance of the minimum distance estimator. An estimate of the covariance matrix of the distance function $g\left(P_{1}, \mathbf{Y}_{T}\right)$ can be obtained from the covariance matrix of the impulse response functions estimated from the VAR under the hypothesis that our structural model is correctly specified. As in the calculation of the standard errors displayed in Figure 1, we estimate this covariance matrix using the algorithm of Berkowitz and Killian (1996). The Jacobian of $g\left(P_{1}, \mathbf{Y}_{T}\right)$ with respect to $P_{1}$ is evaluated numerically at the parameter estimates. 
consumption literature and what is typically assumed in the real-business cycle literature (eg values between one-half and one), but it is smaller than Rotemberg and Woodford's estimate of 6.25. However,

Table 2

\section{Estimates of structural parameters}

\begin{tabular}{||c|c|c||}
\hline Parameter & Estimate & Standard error \\
\hline$\beta$ & 0.99 & 0.001 \\
$\sigma$ & 0.26 & 0.09 \\
$\omega$ & 0.2 & 0.69 \\
$\gamma^{p}$ & 0.56 & 0.11 \\
$\kappa^{p}$ & 0.019 & 0.004 \\
$\kappa^{w}$ & 0.035 & 0.012 \\
$\theta$ & 6.27 & 1.95 \\
$\phi$ & 8.48 & 6.03 \\
\hline
\end{tabular}

since the variable $C$ in our model — as in Rotemberg and Woodford's — proxies for all interest-rate sensitive components of output, and not just non-durable consumption, a value higher than one appears justified. The standard error of $\sigma$ is 0.09 , indicating that this value is fairly well determined by the data, as one would expect from the closeness of fit of the model's output response to the VAR's.

If wages were flexible, our estimate of $\omega$ would imply a Frisch elasticity of labour supply of 5.0, which is about half the size of Rotemberg and Woodford's estimate. ${ }^{16}$ The plausibility of our estimate is difficult to determine from the micro panel data literature, since the functional forms used in that literature are based on first-order conditions derived in a setting with flexible wages. Nonetheless, our estimate is only slightly larger than the highest estimate presented by Mulligan (1998). The standard error of $\omega$ is quite large, but standard-sized confidence intervals still rule out a wide range of interesting cases.

The estimate of $\kappa^{p}$ implies a steady state markup of prices over marginal cost of $19 \%$, which is quite similar to Rotemberg and Woodford's value of $15 \%$. Finally, the estimate of $\kappa^{w}$ implies a steady state markup of the real wage over the marginal rate of substitution of $13 \%$, which, as with our estimate of the steady state price markup, is neither so low nor so high as to be regarded as implausible.

\footnotetext{
16 The elasticity of labour supply is not separately identified in Rotemberg and Woodford's model, even though a similar quantity implicitly appears in their parametrization. Instead, they derive an estimate of this elasticity based on their estimate of $\sigma$ and calibrated values for $a$ and the elasticity of the average real wage with respect to variations in output that are orthogonal to preference and technology shocks.
} 
Figure 2 presents the impulse responses of the four endogenous variables to a monetary policy shock in the model (solid lines) and the VAR (dashed lines). Overall, over the first five quarters after the shock, the responses of the model closely match those of the VAR. The main discrepancies are in the inflation and real wage responses, primarily from the fact that the model cannot replicate, for any parameter values, the hump in inflation three to four quarters after the shock and the hump in the real wage two quarters after the shock.

\subsection{Construction and estimation of shocks}

Rotemberg and Woodford (1997) provide a convenient method for choosing the shock processes, given estimates of the structural parameters. Let $\tilde{Z}_{t}$ denote the model's predictions for the series of endogenous variables, while $\bar{Z}_{t}$ denotes the actual observations of the variables over the sample. Later, when the model is used for simulations, $\bar{Z}_{t}$ and $\tilde{Z}_{t}$ will clearly not coincide. For the purpose of estimating the model under the historical policy rule, however, one would wish $\tilde{Z}_{t}$ to match $\bar{Z}_{t}$ as closely as possible. The law of motion for $\bar{Z}_{t}$ can be obtained by premultiplying the VAR by $T^{-1}$, which yields the reduced form

$$
\bar{Z}_{t}=b+B \bar{Z}_{t-1}+T^{-1} \bar{e}_{t} .
$$

After quasi-differencing and leading by one period, the model's IS equation can be written as

$$
M^{\prime} \tilde{Z}_{t}=\left(M^{\prime}+N^{\prime}\right) E_{t-1} \tilde{Z}_{t+1}+\hat{G}_{t+1}-E_{t-1} \hat{G}_{t+2}
$$

while the equation for wage inflation, after leading by one period, can be written as

$$
P^{\prime} E_{t-1} \tilde{Z}_{t}+R^{\prime} E_{t} \tilde{Z}_{t+1}=\hat{Y}_{t+1}^{w}+\frac{\sigma(1-a)}{\omega+\sigma(1-a)} E_{t}\left(\hat{G}_{t+2}-\hat{G}_{t+1}\right)
$$

and, similarly, the equation for price inflation, after leading by one period, can be written as

$$
V^{\prime} E_{t-1} \tilde{Z}_{t}+W^{\prime} E_{t} \tilde{Z}_{t+1}=\hat{Y}_{t+1}^{p}
$$

where $M, N, P, R, V$ and $W$ are vectors containing the structural parameters. Suppose it were possible to choose $\left\{\hat{G}_{t}, \hat{Y}_{t}^{w}, \hat{Y}_{t}^{p}\right\}$ such that the law of motion for $\left\{\tilde{Z}_{t}\right\}$ implied by equations (34)-(36) coincides exactly with the law of motion for $\left\{\bar{Z}_{t}\right\}$ implied by (33). In this case, the model-consistent, ie rational expectations, in equations (34)-(36) coincide with the expectations implied by the VAR, ie $E_{t} \tilde{Z}_{t+k}=B^{k} \tilde{Z}_{t}$. Conversely, by substituting $\bar{Z}$ for $\tilde{Z}$ and the expectations implied by the VAR for the model-consistent expectations in equations (34)-(36), one can solve for the processes $\left\{\hat{G}_{t}, \hat{Y}_{t}^{w}, \hat{Y}_{t}^{p}\right\}$ with the property that $\tilde{Z}_{t}=\bar{Z}_{t} \forall t$. In fact, given the identification of the series $\left\{\epsilon_{t}\right\}$ with $\left\{\bar{e}_{1 t}\right\}$, all that is required is that the model's implied values for output and price and wage inflation match perfectly those in the data, since then the estimated interest rate rule implies that the model's predicted interest rate is 
also identical to the historical process. The processes that achieve this are given by

$$
\begin{aligned}
{\left[\hat{G}_{t+1}, \hat{Y}_{t+1}^{w}, \hat{Y}_{t+1}^{p}\right]^{\prime} } & =C \bar{Z}_{t-1}+D \bar{e}_{t} \\
C & =\left[\begin{array}{c}
M^{\prime}-N^{\prime} B(I-B)^{-1} \\
P^{\prime}+R^{\prime} B-\frac{\sigma(1-a)}{\omega+\sigma(1-a)}\left(N^{\prime} B-M^{\prime}(I-B)\right) \\
V^{\prime}+W^{\prime} B
\end{array}\right] B \\
D & =\left[\begin{array}{c}
M^{\prime} \\
R^{\prime} B+\frac{\sigma(1-a)}{\omega+\sigma(1-a)}\left(M^{\prime}(I-B)+N^{\prime} B^{2}(I-B)^{-1}\right) \\
W^{\prime} B
\end{array}\right] U .
\end{aligned}
$$

Note that the processes $\left\{\hat{G}_{t}, \hat{Y}_{t}^{w}, \hat{Y}_{t}^{p}\right\}$ so defined depend on the entire vector $\bar{e}_{t}$, which implies that they are not orthogonal to $\bar{e}_{1 t}$. However, orthogonality of $\left\{\hat{G}_{t}, \hat{Y}_{t}^{w}, \hat{Y}_{t}^{p}\right\}$ to the monetary policy shock is a requirement of the theoretical model, as well as necessary in order for the model's implied impulse responses to a monetary policy shock to be independent of the structural disturbances. Hence, in constructing $\left\{\hat{G}_{t}, \hat{Y}_{t}^{w}, \hat{Y}_{t}^{p}\right\}, \bar{e}_{1 t}$ is set to zero at all times. This prevents the model from perfectly replicating $\left\{\bar{Z}_{t}\right\}$, but the structural disturbances still have the property that the variables' responses to $\bar{e}_{2 t}, \bar{e}_{3 t}$ and $\bar{e}_{4 t}$ implied by the model perfectly match those from the VAR. Hence, $L_{2}\left(P_{1}, P_{2}\right)=0$ for any value of $P_{1}$.

A variable that will figure prominently in the welfare analysis in the next section is the Pareto-efficient level of output, $Y_{t}^{e}$, the value of output that would obtain under completely flexible prices and wages. In our model, the Pareto-efficient level of output, or potential output, is given by

$$
\hat{Y}_{t}^{e}=\frac{\omega+\sigma(1-a)}{\omega+a+\sigma(1-a)} \hat{Y}_{t}^{w}+\left(1-\frac{\omega+\sigma(1-a)}{\omega+a+\sigma(1-a)}\right) \hat{Y}_{t}^{p}
$$

where $\hat{Y}_{t}^{e}$ is expressed as a percentage deviation from $\bar{Y}$. More precisely, due to the two-quarter lag in implementing consumption decisions, the variable that figures explicitly in the subsequent welfare analysis is the (two-quarter-ahead) expectation of the output gap, $E_{t-2}\left(\hat{Y}_{t}-\hat{Y}_{t}^{e}\right)$. The standard deviation of the expected output gap over our sample is 3.70, considerably higher than that of expected detrended output (2.17), but smaller than that of expected efficient output (4.90), due to a strong positive correlation (0.7) between expected detrended and efficient output. Whether these features of output are desirable attributes of monetary policy depends upon what affects the welfare of the representative household. To this issue we now turn.

\section{Welfare}

Earlier we emphasised the fact that deriving a structural model from individual optimising behaviour has the advantage that the coefficients in the resulting model equations have a structural interpretation and, if 
the model is correctly specified, should remain invariant under alternative policies. A second advantage of an optimisation-based model is the ability to perform welfare comparisons between alternative policy rules, in that the representative household's lifetime utility provides a model-consistent evaluation criterion. This section provides an approximation to the lifetime utility of the representative household, expressed in terms of a weighted sum of the variances of the endogenous variables. This approximation facilitates the evaluation of the welfare consequences of alternative policies, which is the subject of the remainder of this paper.

\subsection{An expression for the representative household's welfare}

The criterion to be used for evaluating alternative policies is the representative household's welfare, which can be expressed as

$$
W=E\left[\sum_{t=0}^{\infty} \beta^{t}\left(u\left(C_{t} ; \xi_{t}\right)-\int_{0}^{1} v\left(h_{t}^{i} ; \zeta_{t}\right) d i\right)\right]
$$

This objective is the unconditional expectation of the household's lifetime utility (4), where the expectation is taken over all possible histories prior to date zero. Due to the assumption of perfect insurance among households, consumption is identical across households, and hence the first term inside parentheses in (39) does not have a household index attached. The second term in parentheses is understood as an average over possible histories of households' opportunity to change their wages.

In the Appendix, we derive a second-order Taylor approximation of (39) around the same steady state considered in the log-linear approximations in Section 2. This second-order approximation has the advantage that it can be evaluated in terms of the log-linear approximations to the model's exact equilibrium conditions derived in Section 2. Specifically, the approximation can be expressed as

$$
\begin{aligned}
W & =-\Omega\left[\operatorname{var}\left(\pi_{t}\right)+\left(\psi^{p^{-1}}-1\right) \operatorname{var}\left(\pi_{t}-E_{t-2} \pi_{t}\right)+\left(E \pi_{t}\right)^{2}\right. \\
& +c_{1} \operatorname{var}\left(E_{t-2}\left[\hat{Y}_{t}-\hat{Y}_{t}^{e}\right]\right) \\
& \left.+c_{2}\left\{\operatorname{var}\left(\pi_{t}^{w}\right)+\left(\psi^{w^{-1}}-1\right) \operatorname{var}\left(\pi_{t}^{w}-E_{t-2} \pi_{t}^{w}\right)+\left(E \pi_{t}^{w}\right)^{2}\right\}\right] \\
& =-\Omega\left[L+\left(1+c_{2}\right) \bar{\pi}^{2}\right]
\end{aligned}
$$

where $\Omega, c_{1}$ and $c_{2}$ are combinations of the model's parameters, and

$$
\begin{aligned}
L & =\operatorname{var}\left(\pi_{t}\right)+\left(\psi^{p^{-1}}-1\right) \operatorname{var}\left(\pi_{t}-E_{t-2} \pi_{t}\right)+c_{1} \operatorname{var}\left(E_{t-2}\left[\hat{Y}_{t}-\hat{Y}_{t}^{e}\right]\right) \\
& +c_{2}\left[\operatorname{var}\left(\pi_{t}^{w}\right)+\left(\psi^{w^{-1}}-1\right) \operatorname{var}\left(\pi_{t}^{w}-E_{t-2} \pi_{t}^{w}\right)\right]
\end{aligned}
$$

is the welfare loss associated with variability of the output gap and price and wage inflation. In transforming (40) to (41) we made use of the fact that, because the real wage is assumed to be stationary, 
$E\left(\pi_{t}^{w}\right)$ has to equal $\bar{\pi} \equiv E\left(\pi_{t}\right) .{ }^{17}$ The coefficients $c_{1}$ and $c_{2}$ express the weights of output gap and wage inflation variability relative to price inflation variability in (42). For our parameter estimates, and variances expressed as those of annualised quarterly inflation and percent deviations of output from steady state, $c_{1}=0.13$ and $c_{2}=0.89$. The small value of $c_{1}$ implies that an increase in the variance of price inflation is roughly eight times as costly as an equivalent increase in the variance of the output gap.

The presence of the first moment $\bar{\pi}^{2}$ in (41) is due to the fact that even a constant, perfectly anticipated rate of inflation different from zero forces households and firms to adjust their wages and prices whenever they have the opportunity to do so. The implied dispersion of relative prices is welfare reducing because at any point in time the condition that the real wage equals the marginal rate of substitution is violated for most households, and likewise the condition that price equals marginal cost is violated for most firms. The first moment term is important once it is taken into account that nominal interest rates cannot fall below zero in an economy where non-interest bearing money is held. Suppose a given interest rate policy implies an unconditional standard deviation $\sigma(R)$ for the nominal interest rate, and that under such a policy all realisations of the interest rate are confined to an interval of size $k \sigma(R)$ on each side of the steady state value $\bar{R}$. For the zero lower bound on nominal interest rates to hold at all times, $\bar{R} \geq k \sigma(R)$ has to hold. Since $\bar{R}=\bar{\pi}+\rho$, ie the steady state nominal interest rate equals the steady state inflation rate plus the steady state real interest rate, we have $\bar{\pi} \geq k \sigma(R)-\rho$. This last inequality shows that a more volatile interest rate policy can only be implemented at the cost of a higher steady state inflation rate, which reduces welfare. In the results reported below, we take this constraint into account by minimising the objective

$$
W^{R}=-\Omega\left[L+\left(1+c_{2}\right)(\max \{k \sigma(R)-\rho, 0\})^{2}\right]
$$

The values of $k$ and $\rho$ are set to 2.46 and $3.04 \%$ respectively, and have been obtained from the estimated VAR.

\section{Simple rules}

Interest-rate rules that implement the optimal plan for some given objective are generally very complicated. Rotemberg and Woodford (1999) show that, for their model, rules confined to a few terms closely approximate the welfare achieved by unrestricted optimal plans. Also, because simple rules are more transparent, they are more likely to be inferred by private agents, thereby increasing the chance that a committed policy will reap its benefits. The form of simple rule we use is a generalisation of Taylor's

17 Because the second-order approximation (41) is taken around a steady state of zero wage and price inflation, the term $\bar{\pi}^{2}$ has to be small for the approximation to remain valid. 
(1993) rule that includes feedback from wage inflation and lagged interest rates:

$$
\hat{R}_{t}=a \pi_{t}+b \hat{Y}_{t}+c \pi_{t}^{w}+d \hat{R}_{t-1}
$$

This form of rule facilitates direct comparison with most recent analyses of simple rules, for example, many of the papers in Taylor (1999a). In the following subsections, we consider in turn the properties of different special cases of (44), which are distinguished by either imposing specific values for the parameters $a, b, c$ and $d$ or finding the optimal values for those parameters under the constraints of our estimated model. First, as a direct comparison to some of the optimal simple rules recommended in the contributions to the Taylor volume, we compute performance statistics under the prescriptions of four of the rules focused upon by Taylor (1999b) in the robustness analysis he provides. We then compute the optimal feedback parameters in a rule of the form (44).

In their analysis of simple interest rate rules based on a calibrated version of a model similar to ours, Erceg et al (1999) argue that the monetary authority can nearly achieve the optimal plan through the simple policy of responding to inflation and the output gap. The existence of decision lags in our version of their model makes the two-quarter-ahead expectation of the output gap the relevant output variable in the welfare criterion, as shown in (42). Therefore, we also consider rules of the form:

$$
\hat{R}_{t}=a \pi_{t}+b E_{t}\left(\hat{Y}_{t+2}-\hat{Y}_{t+2}^{e}\right)+c \pi_{t}^{w}+d \hat{R}_{t-1}
$$

for the purpose of assessing whether, in the presence of a variance trade-off, allowing the interest rate to respond to both inflation and the output gap (properly measured) can approximate the welfare optimal plan. Since we estimate the current output gap to be much more volatile than the expected output gap and because monetary policy cannot affect current output, including the expected output gap in (45) affords the best opportunity for output to play a non-trivial role in the simple rules we consider. One advantage of considering rules of the form (45) is that, in the presence of variance trade-offs among these variables, we can assess whether the optimal relative weights in the rule match the relative weights given to these variables in the welfare objective. However, it should be noted that from a practical perspective it may be undesirable to adopt a rule that involves a response to the expected output gap. In the light of the difficulty of estimating potential output, especially for the most recent observations, which are precisely the terms that would appear in the reduced-form expression for the expected output gap, rules that respond to the output gap might suffer lower credibility and reduce the benefits gained from commiting to a simple rule. We therefore also consider special cases of (45) that omit responses to the output gap. 


\section{$5.1 \quad$ "Fixed" Taylor rules}

Taylor (1999b) undertakes a robustness analysis of five rules that emerge in the collected papers in Taylor (1999a) as being optimal under some set of conditions (eg model structure, parameter estimates). Our purpose here is to further investigate robustness of these rules in the context of our optimising model with both sticky prices and wages. Our robustness analysis is interesting for the following reason. Among the five rules that Taylor considers, four emerge as (nearly) optimal from one class of models, while the fifth is a product of an entirely different class of model. The distinguishing characteristic between the model classes is not forward-looking behaviour per se. Rather, the two key differences are whether the model builds in exogenous inflation persistence (eg the Fuhrer-Moore model) and whether it includes an output-inflation variance trade-off that is binding from a welfare perspective. In contrast to the other models and welfare criteria, Rotemberg and Woodford's (1999) model and welfare function do not contain these features. Consequently, Taylor finds Rotemberg and Woodford's optimal rule not to be robust when tested with the other models. Since we do not build in exogenous inflation persistence, but our model and welfare function do exhibit variance trade-offs, it is interesting to examine which features are mainly responsible for the comparative results provided by Taylor.

The second to fifth columns of Table 3a present performance measures for our model economy under the rules analysed by Taylor (and are therefore labelled $T_{1}$ to $T_{4}$ ) ${ }^{18}$ For comparison, the first column of the table $(H)$ presents statistics under the historical rule estimated in the VAR. ${ }^{19}$ The last column ( $T_{5}$ ) shows statistics under a rule with the same coefficients as rule $T_{2}$, but with the two-quarter-ahead expected output gap replacing detrended output, ie a rule of the form (45). For each case, the table first presents the coefficients for the interest rate rule, followed by the unconditional variances of the model's endogenous variables, the output gap, the two-quarter-ahead expected output gap, two-quarter-ahead

\footnotetext{
18 Here we do not consider the rule offered by Rotemberg and Woodford (1999). In the next section, we calculate the optimal parameters in (44) under the restriction that $c=0$, which has the same form as Rotemberg and Woodford's rule.

19 The variance of $E_{-2}\left(\hat{Y}-\hat{Y}^{e}\right)$ reported in Table 3 differs from the value reported in Section 3.4. The latter is calculated using the actual (estimated) data series implied by our model and observations on the four endogenous variables, whereas the statistic reported under $H$ in Table 3 is calculated solely using the model and the estimated historical policy rule.
} 
Table 3

Statistics for policy rules

a. Historical and "fixed" Taylor rules

\begin{tabular}{||c|c|c|c|c|c|c||}
\hline & $H$ & $T_{1}$ & $T_{2}$ & $T_{3}$ & $T_{4}$ & $T_{5}$ \\
\hline$a$ & - & 3.00 & 1.20 & 1.50 & 1.50 & 1.20 \\
$b$ & - & 0.80 & 1.00 & 0.50 & 1.00 & 1.00 \\
$d$ & - & - & - & - & - & - \\
$\operatorname{var}(\hat{R})$ & - & 1.00 & 1.00 & - & - & 1.00 \\
$\operatorname{var}(\pi)$ & 6.14 & 6.49 & 6.12 & 14.93 & 14.46 & 6.19 \\
$\operatorname{var}\left(\pi^{w}\right)$ & 2.00 & 0.60 & 1.60 & 6.26 & 5.75 & 0.39 \\
$\operatorname{var}(\hat{Y})$ & 3.94 & 2.93 & 3.88 & 7.91 & 7.63 & 2.07 \\
$\operatorname{var}\left(E_{-2}\left(\hat{Y}-\hat{Y}^{e}\right)\right)$ & 10.76 & 9.65 & 12.46 & 12.38 & 13.45 & 7.75 \\
$\operatorname{var}\left(\pi-E_{-2} \pi\right)$ & 0.43 & 0.24 & 0.35 & 0.59 & 0.59 & 0.24 \\
$\operatorname{var}\left(\pi^{w}-E_{-2} \pi^{w}\right)$ & 2.02 & 1.76 & 1.75 & 1.82 & 1.87 & 1.72 \\
$L$ & 9.52 & 6.56 & 8.90 & 17.50 & 16.92 & 5.32 \\
$\bar{\pi}$ & 3.05 & 3.23 & 3.05 & 6.47 & 6.31 & 3.08 \\
$W^{R}$ & 27.15 & 26.24 & 26.44 & 96.48 & 92.24 & 23.22 \\
\hline
\end{tabular}

b. Optimal rules

\begin{tabular}{||c|c|c|c|c|c|c||}
\hline & $O_{1}$ & $O_{2}$ & $O_{3}$ & $O_{4}$ & $O_{5}$ & $O_{6}$ \\
\hline$a$ & 0.78 & 0.81 & 0.62 & 0.67 & 0.82 & 0.72 \\
$c$ & 0.02 & 0.08 & 0.04 & 0.15 & - & - \\
$d$ & 0.38 & 0.48 & 0.29 & - & 0.38 & - \\
$\operatorname{var}(\hat{R})$ & 1.15 & 1.20 & 1.00 & 1.05 & 1.14 & 1.02 \\
$\operatorname{var}(\pi)$ & 1.59 & 1.59 & 1.65 & 1.58 & 1.59 & 1.57 \\
$\operatorname{var}\left(\pi^{w}\right)$ & 0.46 & 0.47 & 0.45 & 0.39 & 0.46 & 0.37 \\
$\operatorname{var}(\hat{Y})$ & 1.81 & 1.80 & 1.80 & 2.12 & 1.80 & 2.19 \\
$\operatorname{var}\left(E_{-2}\left(\hat{Y}-\hat{Y}^{e}\right)\right)$ & 13.40 & 13.13 & 13.34 & 11.07 & 13.94 & 12.48 \\
$\operatorname{var}\left(\pi-E_{-2} \pi\right)$ & 0.23 & 10.52 & 10.53 & 8.91 & 11.06 & 9.60 \\
$\operatorname{var}\left(\pi^{w}-E_{-2} \pi^{w}\right)$ & 1.38 & 1.40 & 1.47 & 1.70 & 1.38 & 1.69 \\
$L$ & 5.19 & 5.16 & 5.24 & 5.47 & 5.20 & 5.59 \\
$\bar{\pi}$ & 0.06 & 0.06 & 0.12 & 0.05 & 0.06 & 0.04 \\
$W^{R}$ & 5.20 & 5.17 & 5.27 & 5.48 & 5.20 & 5.59 \\
\hline
\end{tabular}

unexpected price inflation, and two-quarter-ahead unexpected wage inflation. The last three rows present our welfare statistics: our measure of welfare that disregards the zero lower bound on nominal interest rates, (42); the level of steady state inflation necessary to avoid the zero lower bound for nominal interest 
rates to be binding; and our modified measure of welfare, (43). The variances of price and wage inflation and the interest rate are expressed in annualised percentage points, while the variances of output and the output gap are measured in percentage deviations from trend. To facilitate comparison, all variances, including those under the historical rule, have been computed under the assumption that no monetary policy shocks are present, ie $\epsilon_{t}=0$ at all times.

One notable result in Table 3a is that historical policy is about as good as any of the Taylor rules from a welfare perspective, which contrasts with the results in Rotemberg and Woodford (1999) that nontrivial welfare gains can be achieved under either $T_{1}$ or $T_{2}$. Part of the reason is that our estimate of the variance of interest rates is relatively smaller in our longer sample. For instance, comparing $H$ to $T_{1}$, the reductions in the variances of price and wage inflation achieved under $T_{1}$ from a strong response to inflation are offset by the lack of sufficient smoothing behaviour which results in more volatile interest rates and higher steady state inflation than that observed historically. Of course, more striking are comparisons to the studies which promoted rules $T_{1}$ to $T_{4}$ in the first place. As in Rotemberg and Woodford (1999), another notable result is that policies that do not involve smoothing (ie $T_{3}$ and $T_{4}$ ) perform substantially worse than the others since the consequent volatility in interest rates (which of course is found to be optimal in these cases) requires a high steady state inflation rate.

Comparing $T_{5}$ to the other rules, the monetary authority can achieve a better welfare outcome by responding to the expected output gap instead of detrended output. This outcome occurs even with a vigorous output response that is seemingly unwarranted in view of the small weight on this term in the welfare function. Naturally, part of the reason for the improved outcome under this rule is a much lower variance for the expected output gap. Lower variances for price and wage inflation also help, and are largely responsible for the better performance of this rule relative to historical practice.

\subsection{Optimal simple rules}

In this subsection, we calculate numerically the optimal coefficients in rules restricted to the simple class of the form (44) and (45). The first column in Table $3 \mathrm{~b}\left(O_{1}\right)$ reports results for the best rule in the class of rules given by (44), ie when all four coefficients, $a, b, c$ and $d$ are chosen to minimise the welfare objective (43). The remaining five columns of the table report results for different cases of (45). ${ }^{20}$

Rule $O_{2}$ places no restrictions on the four response coefficients. Rules $O_{3}, O_{4}$ and $O_{5}$ consider optimal simple rules in three interesting restricted cases of (45). Rule $O_{3}$ is the special case of $d=1$. The results in Taylor (1999b) suggest that rules with $d>1$ can lead to extremely explosive results in many of the

$\overline{20}$ We consider special cases of (45) instead of (44) since, as we will see, $O_{2}$ results in a better welfare outcome than $O_{1}$. 
models analysed in that volume, whereas for some of those same models, a smoothing coefficient of one actually performs very well. We thus consider the welfare consequences of restricting $d$ equal to one, which monetary policymakers may find to be a more robust strategy in the face of model uncertainty. The rules $O_{4}$ and $O_{5}$ correspond to cases where $c$ and $b$, respectively, are set to zero. Rule $O_{4}$ has the same form as Rotemberg and Woodford's optimal simple rule and is the natural benchmark to compare against $T_{5}$ (ie it is the optimised version of rules in the class that $T_{5}$ falls into). We include rule $O_{5}$ to assess the effects of excluding the output gap altogether. Finally, rule $O_{6}$ allows for responses to inflation and the lagged interest rate only. Results under this rule will allow us to assess whether restricting the response of interest rates in this manner - which is nearly optimal in optimising models without variance tradeoffs - entails a substantial welfare loss in the presence of a variance trade-off.

Some common observations can be made about the group of rules $O_{1}$ to $O_{6}$. As in Rotemberg and Woodford, each of the rules is characterised by very low (compared to historical standards) interest rate variability. The low variability is attributable to the high degree of interest rate inertia under all of these rules, and the fact that in our rational expectations model this degree of inertia is both anticipated by agents and credible. Furthermore, the steady state inflation rate $\bar{\pi}$ induced by interest rate variability (as discussed in Section 4.1) is very small, indicating that the welfare gains from further stabilisation that could be achieved by a more variable interest-rate policy are too small to warrant the concomitant increase in $\bar{\pi} .{ }^{21}$ Also, as in Rotemberg and Woodford, the coefficient on the output term - whether it is detrended output in $O_{1}$, which is directly comparable, or the expected output gap - is close to zero (it is actually smaller under $O_{1}, 0.02$, versus their value of 0.06 ). The variance of detrended output is much larger under any of these rules than under the historical one precisely because it is not detrended output that matters either for welfare or for predicting the endogenous variables that do matter for welfare. Interestingly, the variance of the expected output gap is generally not much different from that observed historically, partly as a consequence of the low weight on this term in the welfare objective. Finally, the gain in welfare that is achieved by any of these rules is substantial compared to any of the rules analysed in the previous subsection, including historical policy. The fivefold increase in welfare over historical policy, however, is not nearly as large as the almost fifteenfold increase in welfare that Rotemberg and Woodford report for their more compact welfare function and model.

Turning to the rules individually, the unrestricted simple rules of both forms $\left(O_{1}\right.$ or $\left.O_{2}\right)$ attain the best welfare outcomes. The similar welfare outcomes are attributable to the fact that the optimal response

21 It is interesting to observe that even when we restrict $d$ to be one, the variance of interest rates is much smaller than under rules $T_{1}$ and $T_{2}$. The reason there is such a large difference under $O_{2}$ is that the response to inflation is restrained and the response to output is negligible. That is, if we restrict the smoothing behaviour of the monetary authority, in parallel we should tone down the feedback response to inflation and output to avoid the higher steady-state inflation rate that would be necessary to support more volatile interest rates. 
coefficients are similar and, most importantly for comparing to each other, the responses to output are near zero. ${ }^{22}$ It is interesting to note that the relative size of the optimal coefficients in $O_{2}$ does not exactly correspond to the relative weights given these variables in the welfare criterion. The lack of exact correspondence between the variables that appear in the welfare objective and those that we include in the simple rule, along with the nature of the variance trade-off, does not allow a simple mapping from policymaker objective to instrument rule. The results for $O_{3}$ suggest that imposing the restriction $d=1$ leads to only a small reduction in welfare (approximately $2 \%$ ), which is sufficiently small to likely be offset by concern for adopting a potentially explosive regime. Furthermore, there is a unique and stable equilibrium under this rule even though the response coefficient on inflation is less than one because of the large size of $d$. For rule $O_{4}$, the coefficients on inflation and the lagged interest rate are smaller than Rotemberg and Woodford's, although our coefficients have qualitatively similar implications to theirs; namely, a strong response to inflation, a negligible response to output, and significant smoothing $(d>1)$. Particularly interesting is the smaller size of the response coefficient on inflation compared to rule $\mathrm{O}_{2}$. The reason for this is simple: aggressive stabilisation of price inflation in neglect of wage inflation stabilisation leads to large welfare costs from highly disperse labour supply in the face of volatile wage inflation. It is apparent that neglecting to respond to wage inflation can be costly. The welfare loss from this restricted rule compared to the unrestricted simple rule is $6 \%$ higher. For rule $O_{5}$, as one may expect, excluding output causes only a marginal deterioration in welfare and the optimal response coefficients on the other variables are similar to the unrestricted case. Lastly, eliminating an interest rate response to wage inflation as well as output $\left(O_{6}\right)$ results in a non-trivial deterioration of welfare (8.2\%), a situation that can easily be avoided, especially since various measures of wage data are readily available to monetary policymakers. Thus, our main result for simple rules is: having the monetary authority adopt a highly inertial, though not necessarily explosive, interest rate policy (ie $d \approx 1$ ), which includes responses to price and wage inflation, is nearly optimal from a welfare perspective in the class of simple rules we consider.

\section{Conclusions}

In this paper, we use an estimated version of a small dynamic equilibrium model with nominal rigidities in both product and labour markets to analyse optimal interest rate rules for monetary policy. Our estimates of key parameters, such as the intertemporal elasticities of substitution of both consumption and labour, are close to the ranges of estimates obtained using disaggregated data. Based on our

22 Since higher welfare is obtained under $\mathrm{O}_{2}$, the remainder of the discussion focuses upon special cases of rules of the form (45). 
estimated model, we find that simple rules that include feedback responses from both price and wage inflation and exhibit smoothing, ie a large response to the past level of the interest rate, are nearly optimal from a welfare perspective. Furthermore, even in the presence of a variance trade-off between price and wage inflation and the output gap, we do not find any significant role for the output gap in any rules we consider.

Both our estimation results and our analysis of interest rate rules suggest a number of possible avenues for future research. First, it may be profitable to use data on more labour market series in the light of the relatively large standard errors we obtain for our estimates of the elasticity of labour supply and the degree of market power of workers. Second, a model with other labour market frictions, eg downward nominal wage rigidity, may help determine with more precision parameters that are crucial for the welfare analysis, for example, the elasticity of labour supply. Alternatively, using our estimated standard errors, it would be interesting to consider the effects of parameter uncertainty on optimal interest rate rules. 


\section{A. Log-linear approximations}

\section{A.1 Wage and price inflation}

In this section, we derive equations (23) and (28). The first step is to compute a log-linear approximation to equation (22)). Let $\hat{v}_{t}^{1} \equiv \log \left(W_{t}^{1} / W_{t}\right)$. The ratio $W_{t}^{1} / W_{T}$ can then be approximated as $\hat{v}_{t}^{1}-\sum_{k=1}^{T-t} \pi_{t+k}^{w}$. Similarly, the ratio

$$
\frac{W_{t}^{1}}{P_{T}}=\frac{W_{t}^{1}}{W_{t}} \frac{W_{t}}{P_{t}} \frac{P_{t}}{P_{T}}
$$

is approximated by $\hat{v}_{t}^{1}+\hat{w}_{t}-\sum_{k=1}^{T-t} \pi_{t+k}$. Finally, using the production function (6), the deviation of hours from steady state can be expressed as $\hat{H}_{t}=\frac{1}{1-a}\left(\hat{Y}_{t}-\eta_{t}\right)$.

With this notation, the log-linear approximation of (22) can be written as

$$
E_{t-1} \sum_{T=t}^{\infty}(\lambda \beta)^{T-t}\left\{\omega\left[\frac{\hat{Y}_{T}-\eta_{T}}{1-a}-\tilde{\zeta}_{T}-\phi\left(\hat{v}_{t}^{1}-\sum_{k=1}^{T-t} \pi_{t+k}^{w}\right)\right]-\hat{\lambda}_{T}-\left(\hat{v}_{t}^{1}+\hat{w}_{t}-\sum_{k=1}^{T-t} \pi_{t+k}\right)\right\}=0
$$

where $\tilde{\zeta}_{t} \equiv-\left(v_{h \zeta}(\bar{H} ; 0) / v_{h h}(\bar{H} ; 0) \bar{H}\right) \zeta_{t}$ is the disturbance to the marginal disutility of labour supply. Combining (16) and (19) yields

$$
E_{t-1} \hat{\lambda}_{T}=-\sigma E_{t-1}\left[\hat{Y}_{T}-\hat{G}_{T}\right] \forall T \geq t+1
$$

while taking expectations as of $t-1$ of (15) yields

$$
\begin{aligned}
E_{t-1} \hat{\lambda}_{t} & =E_{t-1}\left[\hat{R}_{t}-\pi_{t+1}+\hat{\lambda}_{t+1}\right] \\
& =E_{t-1}\left[\hat{R}_{t}-\pi_{t+1}-\sigma\left(\hat{Y}_{t+1}-\hat{G}_{t+1}\right)\right] \\
& =-\sigma E_{t-1}\left[\hat{Y}_{t}-\hat{G}_{t}\right]+\nu_{t-1}
\end{aligned}
$$

where

$$
\begin{aligned}
\nu_{t-1} & \equiv E_{t-1}\left[R_{t}-\pi_{t+1}-\sigma\left(\hat{Y}_{t+1}-\hat{Y}_{t}-\hat{G}_{t+1}+\hat{G}_{t}\right)\right] \\
& =E_{t-1} \sum_{T=t}^{\infty}\left(\hat{R}_{T}-\pi_{T+1}\right)-E_{t-2} \sum_{T=t}^{\infty}\left(\hat{R}_{T}-\pi_{T+1}\right)
\end{aligned}
$$

Substituting these expressions for $E_{t-1} \hat{\lambda}_{T}$ into (46) and collecting terms, (46) can be written as

$$
\begin{aligned}
E_{t-1} & \sum_{T=t}^{\infty}(\lambda \beta)^{T-t}\left\{\left(\frac{\omega}{1-a}+\sigma\right) \hat{Y}_{T}-\frac{\omega}{1-a} \eta_{T}-\omega \tilde{\zeta}_{T}-\sigma \hat{G}_{T}\right. \\
& \left.\left.-(1+\omega \phi) \hat{v}_{t}^{1}+\omega \phi \sum_{k=1}^{T-t} \pi_{t+k}^{w}-\hat{w}_{t}+\sum_{k=1}^{T-t} \pi_{t+k}\right)\right\}-\nu_{t-1}=0 .
\end{aligned}
$$

Furthermore, we transform the double summation

$$
\begin{aligned}
\sum_{T=t}^{\infty}(\lambda \beta)^{T-t} \sum_{k=1}^{T-t} \pi_{t+k} & =\sum_{T=t+1}^{\infty}(\lambda \beta)^{T-t} \sum_{k=0}^{\infty}(\lambda \beta)^{k} \pi_{T} \\
& =(1-\lambda \beta)^{-1}\left(\sum_{T=t}^{\infty}(\lambda \beta)^{T-t} \pi_{T}-\pi_{t}\right)
\end{aligned}
$$

The double sum involving $\pi_{t}^{w}$ is transformed analogously.

We next wish to obtain an expression for $\hat{v}_{t}^{1}$ in terms of $\pi_{t}^{w}$. Dividing both sides of (20) by $W_{t}$ and taking the logarithm yields

$$
0 \simeq(1-\lambda) \gamma^{w} \hat{v}_{t}^{1}+(1-\lambda)\left(1-\gamma^{w}\right) \hat{v}_{t}^{2}-\lambda \pi_{t}^{w}
$$


Since $W_{t}^{2}=E_{t-2} W_{t}^{1}$,

$$
\hat{v}_{t}^{2}=E_{t-2} \hat{v}_{t}^{1}-\left(\pi_{t}^{w}-E_{t-2} \pi_{t}^{w}\right)
$$

Substituting this expression into (50) we obtain

$$
\pi_{t}^{w}=\frac{1-\lambda}{\lambda}\left[\gamma^{w} \hat{v}_{t}^{1}+\left(1-\gamma^{w}\right)\left(E_{t-2} \hat{v}_{t}^{1}-\left(\pi_{t}^{w}-E_{t-2} \pi_{t}^{w}\right)\right)\right]
$$

Taking expectations as of $t-2$ on both sides, $E_{t-2} \pi_{t}^{w}=\frac{1-\lambda}{\lambda} E_{t-2} \hat{v}_{t}^{1}$ and hence

$$
\frac{1-\lambda}{\lambda} \hat{v}_{t}^{1}=\frac{1}{\psi^{w}} \pi_{t}^{w}-\frac{1-\psi^{w}}{\psi_{w}} E_{t-2} \pi_{t}^{w}
$$

where $\psi^{w} \equiv \gamma^{w} \lambda /\left(1-\gamma^{w}(1-\lambda)\right)$ is defined as in (23). Substituting (53) for $\hat{v}_{t}^{1}$ in (49) and using the transformation for the double sums and the fact that $E_{t-1} \nu_{t+j}=0 \forall j \geq 0$ we obtain (23).

The derivation of (28) involves the same steps as above. Let $\hat{p}_{t}^{1} \equiv \log \left(p_{t}^{1} / P_{t}\right)$. Then (27) can be approximated as

$$
E_{t-1} \sum_{T=t}^{\infty}(\alpha \beta)^{T-t}\left\{\frac{1-a+\theta a}{1-a} \hat{p}_{t}^{1}-\frac{1}{1-a}\left(a \hat{Y}_{T}-\eta_{T}\right)-\hat{w}_{t}-\sum_{k=1}^{T-t} \pi_{t+k}^{w}-\frac{\theta a}{1-a} \sum_{k=1}^{T-t} \pi_{t+k}\right\}=0 .
$$

The double sums in (54) are being transformed as before. Furthermore, dividing (25) by $P_{t}$ and taking the logarithm, and using the fact that $p_{t}^{2}=E_{t-2} p_{t}^{1}$, we can derive an expression for $\hat{p}_{t}^{1}$ in terms of $\pi_{t}$ analogous to (53),

$$
\frac{1-\alpha}{\alpha} \hat{p}_{t}^{1}=\frac{1}{\psi^{p}} \pi_{t}-\frac{1-\psi^{p}}{\psi_{p}} E_{t-2} \pi_{t}
$$

where $\psi^{p} \equiv \gamma^{p} \alpha /\left(1-\gamma^{p}(1-\alpha)\right)$ is defined as in (28). Substituting (55) for $\hat{p}_{t}^{1}$ in (54) and using the transformation for the double sums we obtain (28).

\section{A.2 The representative household's welfare}

In this section, we derive the second-order approximation (40) to the representative household's welfare (39), using some results of Rotemberg and Woodford's (1997) Appendix 3. Specifically, we form a second-order Taylor series expansion of (39) around the steady state characterised by the efficient output level $\bar{Y}$ defined in (12) and zero wage and price inflation. Hence, we form the approximation around the same steady state around which the model's exact equilibrium conditions have been $\log$-linearised.

Since the demand side of our model is identical to Rotemberg and Woodford's, the second-order approximation of $u\left(C_{t} ; \xi_{t}\right)$ is identical to their equation (9.10) as well, which we reproduce here:

$$
u\left(C_{t} ; \xi_{t}\right)=u_{c} \bar{Y} \hat{Y}_{t}+\frac{1}{2}\left(u_{c} \bar{Y}+u_{c c} \bar{Y}^{2}\right) \hat{Y}_{t}^{2}-u_{c c} \bar{Y}^{2} \hat{G}_{t} \hat{Y}_{t}+u n f+t i p+\mathcal{O}\left(\|\xi\|^{3}\right)
$$

where $u n f$ stands for terms that are unforecastable two periods ahead (since in our model monetary policy affects output only with a lag of two periods), and tip denotes terms that are independent of monetary policy. $\|\xi\|$ is a bound on the amplitude of fluctuations in the exogenous disturbances, which we take to be the same for $\xi, \zeta$, and $\eta$. The term $\mathcal{O}\left(\|\xi\|^{3}\right)$ indicates that terms of third or higher order in the deviations of the various variables from their steady-state values are being neglected.

Similarly, a second-order approximation of household $i$ 's disutility of labour supply is given by

$$
v\left(h_{t}^{i} ; \zeta_{t}\right)=v_{h} \bar{H} \hat{h}_{t}^{i}+\frac{1}{2}\left(v_{h} \bar{H}+v_{h h} \bar{H}^{2}\right) \hat{h}_{t}^{i 2}-v_{h h} \bar{H}^{2} \tilde{\zeta}_{t} \hat{h}_{t}^{i}+t i p+\mathcal{O}\left(\|\xi\|^{3}\right)
$$


Integrating this expression over $i$ yields

$$
\begin{aligned}
& \int_{0}^{1} v\left(h_{t}^{i} ; \zeta_{t}\right) d i=v_{h} \bar{H} E_{i}\left[\hat{h}_{t}^{i}\right] \\
& \quad+\frac{1}{2}\left(v_{h} \bar{H}+v_{h h} \bar{H}^{2}\right)\left(E_{i}\left[\hat{h}_{t}^{i}\right]^{2}+\operatorname{var}_{i}\left(\hat{h}_{t}^{i}\right)\right)-v_{h h} \bar{H}^{2} \tilde{\zeta}_{t} E_{i}\left[\hat{h}_{t}^{i}\right]+t i p+\mathcal{O}\left(\|\xi\|^{3}\right) .
\end{aligned}
$$

By integrating (7) over $z$, we obtain

$$
H_{t}=\left[\int_{0}^{1}\left(h_{t}^{i}\right)^{\frac{\phi-1}{\phi}} d i\right]^{\frac{\phi}{\phi-1}} .
$$

Using this expression and the fact that for a random variable $X, \log E[X]=E[\log X]+\frac{1}{2} \operatorname{var}(\log X)$, we obtain that

$$
\hat{H}_{t} \equiv \log \left(H_{t} / \bar{H}\right)=E_{i}\left[\hat{h}_{t}^{i}\right]+\frac{\phi-1}{2 \phi} \operatorname{var}_{i}\left(\hat{h}_{t}^{i}\right) .
$$

Solving (60) for $E_{i}\left[\hat{h}_{t}^{i}\right]$ and substituting in (58) yields

$$
\begin{aligned}
\int_{0}^{1} v & \left(h_{t}^{i} ; \zeta_{t}\right) d i=v_{h} \bar{H} \hat{H}_{t}+\frac{v_{h} \bar{H}}{2}(1+\omega) \hat{H}_{t}^{2} \\
& +\frac{v_{h} \bar{H}}{2}\left(\phi^{-1}+\omega\right) \operatorname{var}_{i}\left(\hat{h}_{t}^{i}\right)-v_{h h} \bar{H}^{2} \tilde{\zeta}_{t} \hat{H}_{t}+t i p+\mathcal{O}\left(\|\xi\|^{3}\right)
\end{aligned}
$$

where $\omega$ is defined as in (23).

We next wish to substitute for $\hat{H}_{t}$ in (61) in terms of output. To do so, note first that the definition of $H_{t}=\int_{0}^{1} H_{t}(z) d z$ implies that

$$
\hat{H}_{t}=E_{z}\left[\hat{H}_{t}(z)\right]+\frac{1}{2} \operatorname{var}_{z}\left(\hat{H}_{t}(z)\right) .
$$

Firms' production function in turn implies that

$$
E_{z}\left[\hat{H}_{t}(z)\right]=(1-a)^{-1}\left(E_{z}\left[\hat{y}_{t}(z)\right]-\eta_{t}\right), \operatorname{var}_{z}\left(\hat{H}_{t}(z)\right)=(1-a)^{-2} \operatorname{var}_{z}\left(\hat{y}_{t}(z)\right)
$$

and therefore

$$
\hat{H}_{t}=(1-a)^{-1}\left(E_{z}\left[\hat{y}_{t}(z)\right]-\eta_{t}\right)+\frac{1}{2(1-a)^{2}} \operatorname{var}_{z}\left(\hat{y}_{t}(z)\right) .
$$

Finally, deriving an expression for $\hat{Y}_{t}$ analogous to (62), substituting from this expression for $E_{z}\left[\hat{y}_{t}(z)\right]$ in (64), and substituting the resulting expression for $\hat{H}_{t}$ into (61) yields

$$
\begin{aligned}
& \int_{0}^{1} v\left(h_{t}^{i} ; \zeta_{t}\right) d i=\frac{v_{h} \bar{H}}{1-a}\left[\hat{Y}_{t}+\frac{1+\omega}{2(1-a)} \hat{Y}_{t}^{2}\right]-\frac{v_{h} \bar{H}}{1-a}\left[\omega \tilde{\zeta}_{t} \hat{Y}_{t}+\frac{1+\omega}{1-a} \eta_{t} \hat{Y}_{t}\right] \\
& +\frac{v_{h} \bar{H}}{1-a}\left[\frac{1}{2}\left(\frac{1}{1-a}-\frac{\theta-1}{\theta}\right) \operatorname{var}_{z}\left(\hat{y}_{t}(z)\right)+\frac{1-a}{2}\left(\phi^{-1}+\omega\right) \operatorname{var}_{i}\left(\hat{h}_{t}^{i}\right)\right]+\operatorname{tip}+\mathcal{O}\left(\|\xi\|^{3}\right)
\end{aligned}
$$

Because the efficient steady-state level of output is characterised by (12), it follows that

$$
\frac{v_{h} \bar{H}}{1-a}=u_{c} \bar{Y}
$$

Hence,

$$
\begin{aligned}
u\left(C_{t} ; \xi_{t}\right)-\int_{0}^{1} v\left(h_{t}^{i} ; \zeta_{t}\right) d i=u_{c} \bar{Y}\left[\frac{\omega+a+\sigma(1-a)}{1-a}\left(\hat{Y}_{t} \hat{Y}_{t}^{e}-\frac{1}{2} \hat{Y}_{t}^{2}\right)\right. \\
\left.-\frac{1}{2}\left(\frac{1}{1-a}-\frac{\theta-1}{\theta}\right) \operatorname{var}_{z}\left(\hat{y}_{t}(z)\right)-\frac{1-a}{2}\left(\phi^{-1}+\omega\right) \operatorname{var}_{i}\left(\hat{h}_{t}^{i}\right)\right]+t i p+\mathcal{O}\left(\|\xi\|^{3}\right)
\end{aligned}
$$

where $\hat{Y}_{t}^{e}$ is the efficient level of output defined in (38). Noting that $\hat{Y}_{t}^{e}$ is independent of policy, and using the fact that interest rates affect output only with a lag of two periods, (66) can be rewritten as

$$
u\left(C_{t} ; \xi_{t}\right)-\int_{0}^{1} v\left(h_{t}^{i} ; \zeta_{t}\right) d i=-\frac{u_{c} \bar{Y}}{2}\left[\frac{\omega+a+\sigma(1-a)}{1-a}\left(E_{t-2}\left[\hat{Y}_{t}-\hat{Y}_{t}^{e}\right]\right)^{2}\right.
$$




$$
\left.+\left(\frac{1}{1-a}-\frac{\theta-1}{\theta}\right) \operatorname{var}_{z}\left(\hat{y}_{t}(z)\right)+(1-a)\left(\phi^{-1}+\omega\right) \operatorname{var}_{i}\left(\hat{h}_{t}^{i}\right)\right]+u n f+\operatorname{tip}+\mathcal{O}\left(\|\xi\|^{3}\right)
$$

We now wish to substitute for the terms $\operatorname{var}_{z}\left(\hat{y}_{t}(z)\right)$ and $\operatorname{var}_{i}\left(\hat{h}_{t}^{i}\right)$. From the demand functions for households' labour services (9) and producers' goods (10) it follows that

$$
\operatorname{var}_{z}\left(\hat{y}_{t}(z)\right)=\theta^{2} \operatorname{var}_{z}\left(\log p_{t}(z)\right)
$$

and

$$
\operatorname{var}_{i}\left(\hat{h}_{t}^{i}\right)=\phi^{2} \operatorname{var}_{i}\left(\log W_{t}^{i}\right)
$$

Let $\bar{p}_{t} \equiv E_{z} \log p_{t}(z)$ and $\Delta_{t} \equiv \operatorname{var}_{z}\left(\log p_{t}(z)\right)$. Then

$$
\begin{aligned}
\Delta_{t} & =\operatorname{var}_{z}\left(\log p_{t}(z)-\bar{p}_{t-1}\right) \\
& =E_{z}\left[\left(\log p_{t}(z)-\bar{p}_{t-1}\right)^{2}\right]-\Delta \bar{p}_{t}^{2} \\
& =\alpha \Delta_{t-1}+(1-\alpha) \gamma^{p}\left(\log p_{t}^{1}-\bar{p}_{t-1}\right)^{2}+(1-\alpha)\left(1-\gamma^{p}\right)\left(\log p_{t}^{2}-\bar{p}_{t-1}\right)^{2}-\Delta \bar{p}_{t}^{2}
\end{aligned}
$$

where the last equation made use of the price index (25) in log-linearised form. From (25) it also follows that

$$
\Delta \bar{p}_{t}=(1-\alpha) \gamma^{p}\left(\log p_{t}^{1}-\bar{p}_{t-1}\right)+(1-\alpha)\left(1-\gamma^{p}\right)\left(\log p_{t}^{2}-\bar{p}_{t-1}\right) .
$$

Taking expectations as of $t-2$ on both sides of (71), and using the fact that $\log p_{t}^{2}=E_{t-2} \log p_{t}^{1}+\mathcal{O}\left(\|\xi\|^{2}\right)$,

$$
E_{t-2} \Delta \bar{p}_{t}=(1-\alpha)\left(\log p_{t}^{2}-\bar{p}_{t-1}\right)+\mathcal{O}\left(\|\xi\|^{2}\right)
$$

Substituting (72) into (71), we obtain

$$
\Delta \bar{p}_{t}-\left(1-\gamma^{p}\right) E_{t-2} \Delta \bar{p}_{t}=(1-\alpha) \gamma^{p}\left(\log p_{t}^{1}-\bar{p}_{t-1}\right)
$$

Finally, squaring both sides of (72) and (73), and using $\Delta \bar{p}_{t}=\pi_{t}+\mathcal{O}\left(\|\xi\|^{2}\right)$, (70) can be written as

$$
\begin{aligned}
\Delta_{t} & =\alpha \Delta_{t-1}+\frac{1}{(1-\alpha) \gamma^{p}}\left(\pi_{t}-\left(1-\gamma^{p}\right) E_{t-2} \pi_{t}\right)^{2}+\frac{1-\gamma^{p}}{\alpha \gamma^{p}}\left(E_{t-2} \pi_{t}\right)^{2}-\pi_{t}^{2}+\mathcal{O}\left(\|\xi\|^{3}\right) \\
& =\alpha \Delta_{t-1}+\frac{\alpha}{1-\alpha}\left[\pi_{t}^{2}+\left(\psi^{p^{-1}}-1\right)\left(\pi_{t}-E_{t-2} \pi_{t}\right)^{2}\right]+\mathcal{O}\left(\|\xi\|^{3}\right)
\end{aligned}
$$

where $\psi^{p}$ is defined as in (28).

If $\Delta_{-1}$ is considered independent of policy, it follows that

$$
\begin{aligned}
\sum_{t=0}^{\infty} \beta^{t} \Delta_{t} & =\sum_{t=0}^{\infty} \beta^{t} \sum_{s=0}^{t} \alpha^{t-s} \frac{\alpha}{1-\alpha}\left[\pi_{s}^{2}+\left(\psi^{p^{-1}}-1\right)\left(\pi_{s}-E_{s-2} \pi_{s}\right)^{2}\right]+t i p+\mathcal{O}\left(\|\xi\|^{3}\right) \\
& =\frac{\alpha}{(1-\alpha)(1-\alpha \beta)} \sum_{t=0}^{\infty} \beta^{t}\left[\pi_{t}^{2}+\left(\psi^{p^{-1}}-1\right)\left(\pi_{t}-E_{t-2} \pi_{t}\right)^{2}\right]+t i p+\mathcal{O}\left(\|\xi\|^{3}\right)
\end{aligned}
$$

By defining $\Delta_{t}^{w} \equiv v a r_{i}\left(\log W_{t}^{i}\right)$ and following the same steps as above, we can derive the analogous expression

$$
\sum_{t=0}^{\infty} \beta^{t} \Delta_{t}^{w}=\frac{\lambda}{(1-\lambda)(1-\lambda \beta)} \sum_{t=0}^{\infty} \beta^{t}\left[\left(\pi_{t}^{w}\right)^{2}+\left(\psi^{w^{-1}}-1\right)\left(\pi_{t}^{w}-E_{t-2} \pi_{t}^{w}\right)^{2}\right]+t i p+\mathcal{O}\left(\|\xi\|^{3}\right) .
$$

Combining (67) to (69), (75), and (76), and noting that

$$
(1-a)\left(\phi^{-1}+\omega\right) \phi^{2} \frac{\lambda}{(1-\lambda)(1-\lambda \beta)}=\frac{\phi(\omega+\sigma(1-a))}{\kappa^{w}}
$$


and

we obtain (40), where

$$
\left(\frac{1}{1-a}-\frac{\theta-1}{\theta}\right) \theta^{2} \frac{\alpha}{(1-\alpha)(1-\alpha \beta)}=\frac{\theta a}{\kappa^{p}(1-a)}
$$

and

$$
\begin{gathered}
\Omega \equiv \frac{u_{c} \bar{Y}}{2(1-\beta)} \frac{\theta a}{\kappa^{p}(1-a)} \\
c_{1} \equiv\left[\frac{\theta a}{\kappa^{p}(1-a)}\right]^{-1} \frac{\omega+a+\sigma(1-a)}{1-a}
\end{gathered}
$$

$$
c_{2} \equiv\left[\frac{\theta a}{\kappa^{p}(1-a)}\right]^{-1} \frac{\phi(\omega+\sigma(1-a))}{\kappa^{w}} .
$$




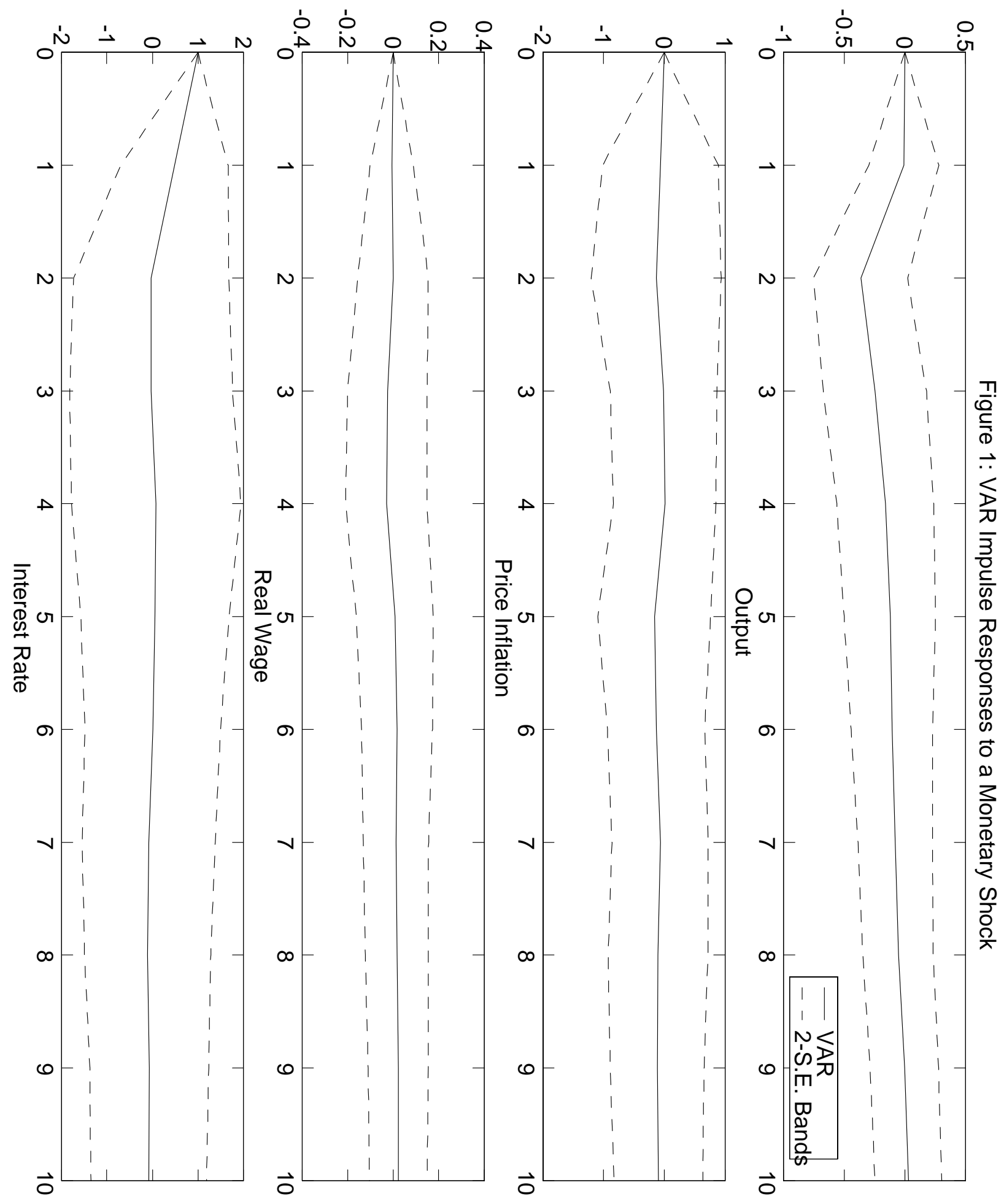




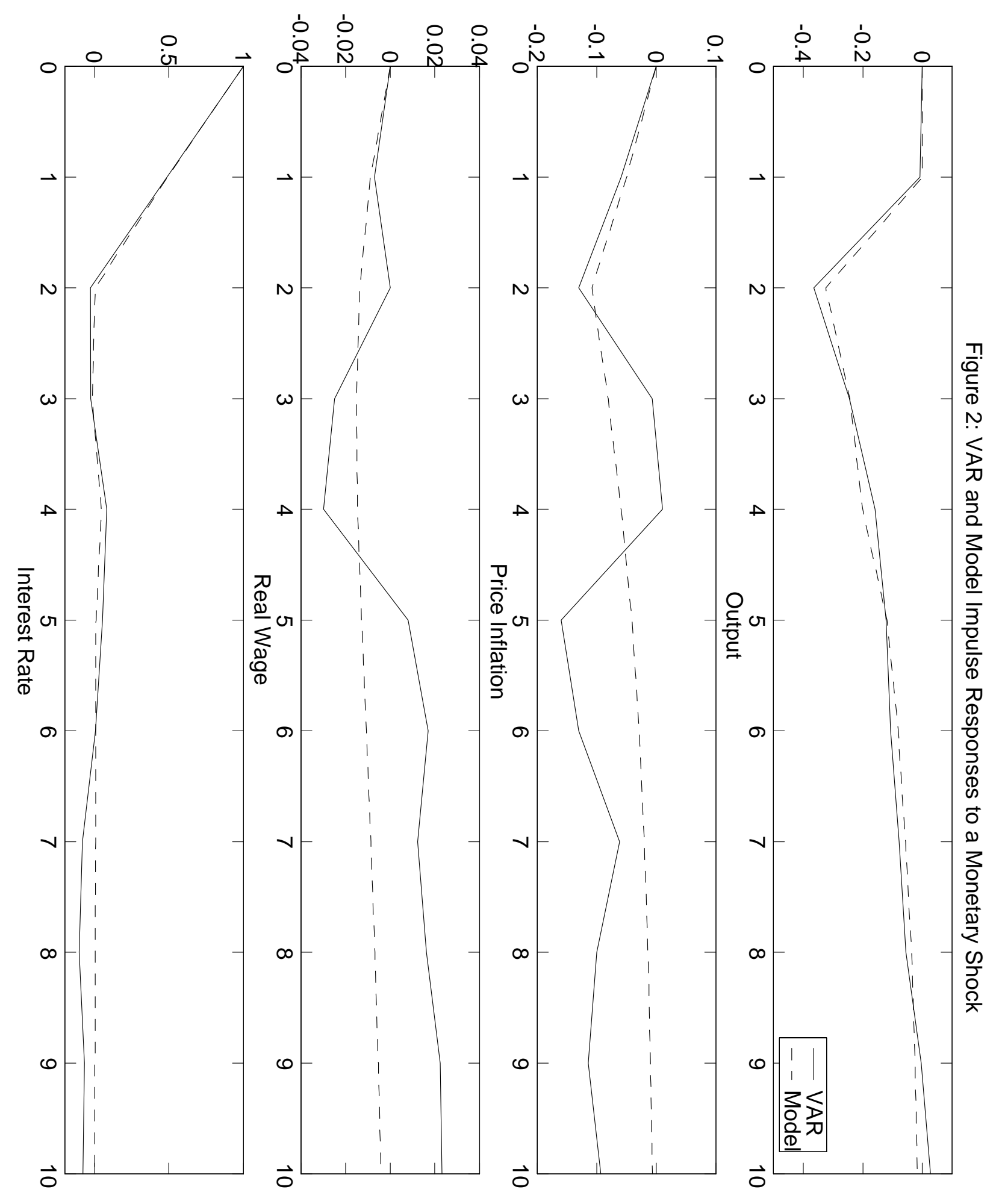




\section{References}

Amato, Jeffery D and Thomas Laubach (1999): "The Value of Interest Rate Smoothing: How the Private Sector Helps the Federal Reserve". Forthcoming, Federal Reserve Bank of Kansas City Economic Review.

Batini, Nicoletta and Andrew G Haldane (1999): "Forward-looking Rules for Monetary Policy”, in John B Taylor (ed), Monetary Policy Rules, NBER and Chicago University Press.

Berkowitz, Jeremy and Lutz Kilian (1996): "Recent Developments in Bootstrapping Time Series". Manuscript.

Bernanke, Ben S and Ilian Mihov (1998): "Measuring Monetary Policy". Quarterly Journal of Economics 113, pp 869-902.

Calvo, Guillermo A (1983): "Staggered Prices in a Utility-Maximising Framework". Journal of Monetary Economics 12, pp 383-98.

Christiano, Lawrence J, Martin Eichenbaum and Charles L Evans (1997): "Sticky Price and Limited Participation Models of Money: A Comparison”. European Economic Review 41, pp 1201-49.

Erceg, Christopher J (1997): "Nominal Wage Rigidities and the Propagation of Monetary Disturbances". Board of Governors International Finance Discussion Paper No 590, September.

Erceg, Christopher J, Dale W Henderson and Andrew T Levin (1999): “Optimal Monetary Policy with Staggered Wage and Price Conrtracts". Board of Governors International Finance Discussion Paper No 635, April.

Ireland, Peter N (1997): "A small, structural, quarterly model for monetary policy evaluation". Carnegie-Rochester Conference Series on Public Policy 47, pp 83-108.

Ireland, Peter N (1998): "A Method for Taking Models to the Data”. Manuscript, November.

Kim, Jinill (1999): "Constructing and Estimating a Realistic Optimising Model of Monetary Policy". Forthcoming, Journal of Monetary Economics.

Leeper, Eric M, Christopher A Sims and Tao Zha (1996): “What Does Monetary Policy Do?". Brookings Papers on Economic Activity, pp 1-63.

Lucas, Robert E (1976): "Econometric Policy Evaluation: A Critique". Carnegie-Rochester Conference Series on Public Policy 1, pp 14-46. 
Mulligan, Casey B (1998): “Substitution over Time: Another Look at Life-Cycle Labor Supply”, in Ben S Bernanke and Julio J Rotemberg (eds), NBER Macroeconomics Annual.

Rotemberg, Julio J and Michael Woodford (1997): “An Optimisation-Based Econometric Framework for the Evaluation of Monetary Policy", in Ben S Bernanke and Julio J Rotemberg (eds), NBER Macroeconomics Annual, pp 297-346. Expanded version circulated as NBER Technical Working Paper No 233, May 1998.

Rotemberg, Julio J and Michael Woodford (1999): "Interest-Rate Rules in an Estimated Sticky Price Model”, in John B Taylor (ed), Monetary Policy Rules, NBER and Chicago University Press.

Taylor, John B (1993): "Discretion Versus Policy Rules in Practice". Carnegie-Rochester Conference Series on Public Policy 39, pp 195-214.

Taylor, John B (1999a): (ed) Monetary Policy Rules, NBER and Chicago University Press.

Taylor, John B (1999b): “Introduction”, in John B Taylor (ed), Monetary Policy Rules, NBER and Chicago University Press.

Woodford, Michael (1999a): "Inflation Stabilisation and Welfare". Ch. 6 in Interest and Prices, manuscript, May.

Woodford, Michael (1999b): "Optimal Monetary Policy Inertia". NBER Working Paper No 7261, August. 



\section{Recent BIS Working Papers}

\begin{tabular}{|c|c|c|}
\hline No & Title & Author \\
\hline $\begin{array}{l}71 \\
\text { June } 1999\end{array}$ & The term structure of announcement effects & $\begin{array}{l}\text { Michael J Fleming } \\
\text { and Eli M Remolona }\end{array}$ \\
\hline $\begin{array}{l}72 \\
\text { August } 1999\end{array}$ & Reserve currency allocation: an alternative methodology & $\begin{array}{l}\text { Srichander } \\
\text { Ramaswamy }\end{array}$ \\
\hline $\begin{array}{l}73 \\
\text { August } 1999\end{array}$ & $\begin{array}{l}\text { The Taylor rule and interest rates in the EMU area: a } \\
\text { note }\end{array}$ & $\begin{array}{l}\text { Stefan Gerlach and } \\
\text { Gert Schnabel }\end{array}$ \\
\hline $\begin{array}{l}74 \\
\text { August } 1999\end{array}$ & The dollar-mark axis & Gabriele Galati \\
\hline $\begin{array}{l}75 \\
\text { August } 1999\end{array}$ & $\begin{array}{l}\text { A note on the Gordon growth model with nonstationary } \\
\text { dividend growth }\end{array}$ & Henri Pagès \\
\hline $\begin{array}{l}76 \\
\text { October } 1999\end{array}$ & $\begin{array}{l}\text { The price of risk at year-end: evidence from interbank } \\
\text { lending }\end{array}$ & Craig H Furfine \\
\hline $\begin{array}{l}77 \\
\text { October } 1999\end{array}$ & $\begin{array}{l}\text { Perceived central bank intervention and market } \\
\text { expectations: an empirical study of the yen/dollar } \\
\text { exchange rate, 1993-96 }\end{array}$ & $\begin{array}{l}\text { Gabriele Galati and } \\
\text { William Melick }\end{array}$ \\
\hline $\begin{array}{l}78 \\
\text { October } 1999\end{array}$ & Banking and commerce: a liquidity approach & $\begin{array}{l}\text { Joseph G Haubrich } \\
\text { and João A C Santos }\end{array}$ \\
\hline $\begin{array}{l}79 \\
\text { November } 1999\end{array}$ & $\begin{array}{l}\text { Pass-through of exchange rates and import prices to } \\
\text { domestic inflation in some industrialised economies }\end{array}$ & Jonathan McCarthy \\
\hline $\begin{array}{l}80 \\
\text { November } 1999\end{array}$ & A note on alternative measures of real bond rates & Palle S Andersen \\
\hline $\begin{array}{l}81 \\
\text { November } 1999\end{array}$ & Interbank interest rates and the risk premium & Henri Pagès \\
\hline $\begin{array}{l}82 \\
\text { November } 1999\end{array}$ & $\begin{array}{l}\text { Sacrifice ratios and the conduct of monetary policy in } \\
\text { conditions of low inflation }\end{array}$ & $\begin{array}{l}\text { Palle S Andersen and } \\
\text { William L Wascher }\end{array}$ \\
\hline $\begin{array}{l}83 \\
\text { January } 2000\end{array}$ & $\begin{array}{l}\text { Switching from single to multiple bank lending } \\
\text { relationships: determinants and implications }\end{array}$ & $\begin{array}{l}\text { Luísa A Farinha and } \\
\text { João A C Santos }\end{array}$ \\
\hline $\begin{array}{l}84 \\
\text { January } 2000\end{array}$ & $\begin{array}{l}\text { What have we learned from recent financial crises and } \\
\text { policy responses? }\end{array}$ & William R White \\
\hline $\begin{array}{l}85 \\
\text { January } 2000\end{array}$ & $\begin{array}{l}\text { A defence of the expectations theory as a model of US } \\
\text { long-term interest rates }\end{array}$ & Gregory D Sutton \\
\hline $\begin{array}{l}86 \\
\text { March } 2000\end{array}$ & $\begin{array}{l}\text { Information, liquidity and risk in the international } \\
\text { interbank market: implicit guarantees and private credit } \\
\text { market failure }\end{array}$ & $\begin{array}{l}\text { Henri Bernard and } \\
\text { Joseph Bisignano }\end{array}$ \\
\hline
\end{tabular}




ISSN 1020-0959 